\title{
THE EFFECT OF EARLY THERAPEUTIC ALLIANCE ON TREATMENT DROPOUT IN COGNITIVE PROCESSING THERAPY AND CLIENT FACTORS AS MODERATORS OF THIS RELATIONSHIP
}

\author{
by \\ Iris Sijercic \\ Bachelor of Arts Honours in Psychology, York University, 2014 \\ A thesis presented to Ryerson University \\ in partial fulfillment of the requirements for the degree of \\ Master of Arts in the program of Psychology
}

Toronto, Ontario, Canada, 2018

(C) Iris Sijercic, 2018 


\section{RYERSON UNIVERSITY \\ YEATES SCHOOL OF GRADUATE STUDIES \\ AUTHOR'S DECLARATION FOR SUBMISSION OF A THESIS}

I hereby declare that I am the sole author of this thesis. This is a true copy of the thesis, including any required final revisions, as accepted by my examiners.

I authorize Ryerson University to lend this thesis to other institutions or individuals for the purpose of scholarly research.

I further authorize Ryerson University to reproduce this thesis by photocopying or by other means, in total or part, at the request of other institutions or individuals for the purpose of scholarly research.

I understand that my thesis may be made electronically available to the public. 
The Effect of Early Therapeutic Alliance on Treatment Dropout in Cognitive Processing Therapy and Client Factors as Moderators of This Relationship

Master of Arts, 2018

Iris Sijercic

Psychology

Ryerson University

\begin{abstract}
Although efficacious treatments, including Cognitive Processing Therapy (CPT), are available for treating Posttraumatic Stress Disorder (PTSD), a substantial number of clients do not receive a full course of CPT due to clients dropping out prematurely. Examining factors associated with treatment dropout may increase our understanding on how to tailor interventions to prevent treatment dropout. This study examined the relationship between early therapeutic alliance and treatment dropout, and client age and pretreatment PTSD symptom severity as predictors of dropout and moderators of the alliance-dropout association. Clients were part of a larger randomized implementation trial, and either began CPT and dropped out $(n=38)$ or completed 12 sessions of CPT $(n=74)$. Results indicated early therapeutic alliance did not significantly predict treatment dropout, and age and PTSD severity were not significant predictors or moderators of the alliance-dropout association. Clinical implications of the findings are discussed.
\end{abstract}




\section{Acknowledgements}

I would like to express my sincerest gratitude to my research supervisor, Dr. Candice Monson. Your guidance and countless hours spent providing me with mentorship eased my nerves and made me feel incredibly supported throughout this process. I am very grateful for Dr. Maya Roth's commitment to being on my supervisory committee and for her helpful feedback. I would also like to thank Dr. Janice Kuo, for serving on my examination committee.

To the IMPACT Lab, thank you all for the work that you have done that made this project possible. To the members of my cohort, I am beyond grateful to have met such an amazing group of like-minded individuals and look forward to many more years of laughter with you.

I would like to thank my parents for their unwavering support and unconditional love. Without you, I would not be where I am today. To Steven, thank you for being my rock and always believing in me. Lastly, thank you to my best friends, for supporting me throughout this journey. 


\section{Table of Contents}

Author's Declaration for Electronic Submission of a Thesis ..................................................ii

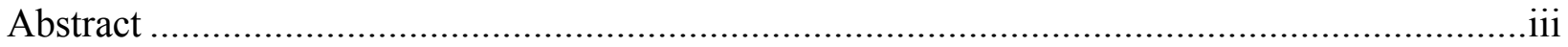

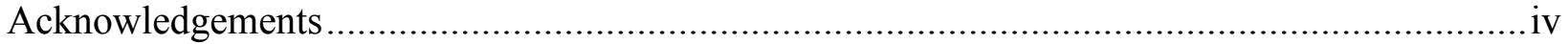

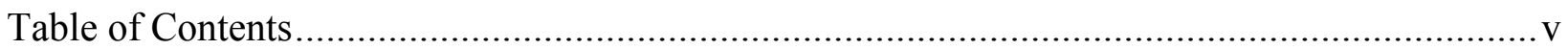

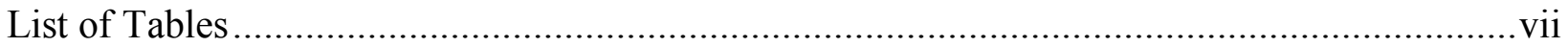

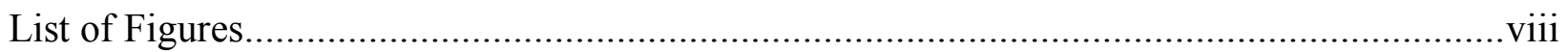

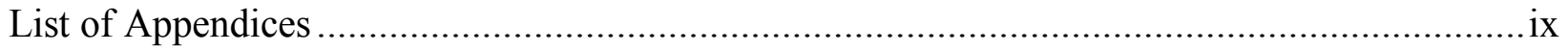

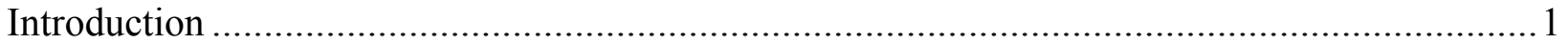

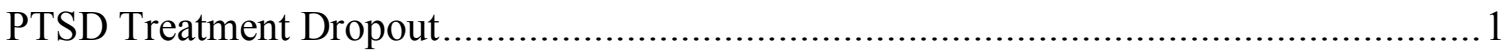

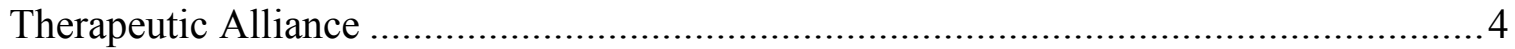

Moderators of Therapeutic Alliance and Treatment Dropout...................................... 8

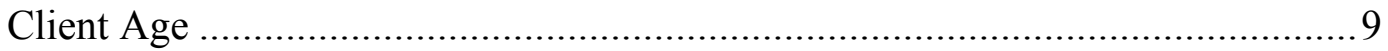

Client Pretreatment PTSD Symptom Severity ........................................ 10

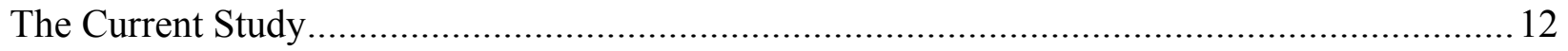

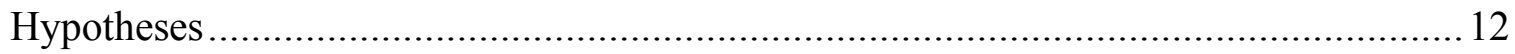

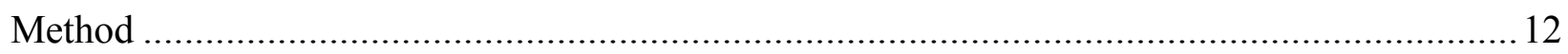

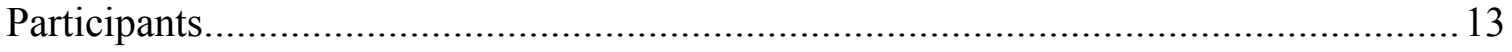

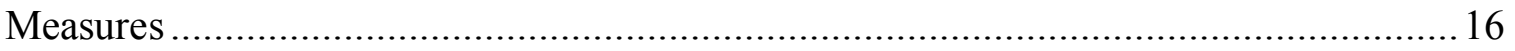

Working Alliance Inventory-Observer Version-Short Form ....................... 16

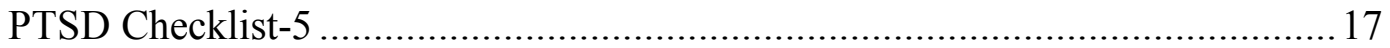

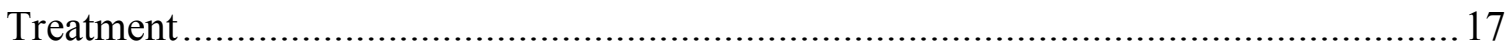

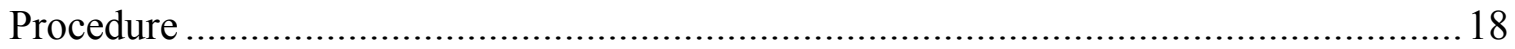




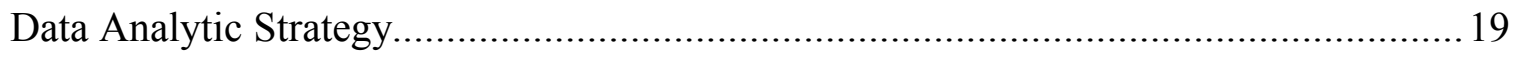

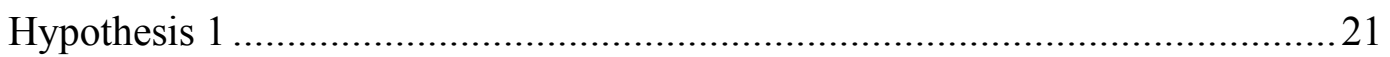

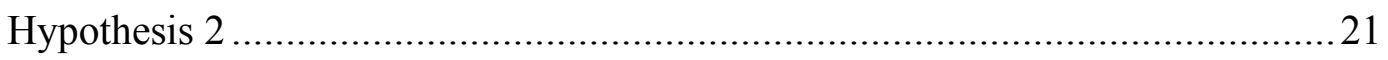

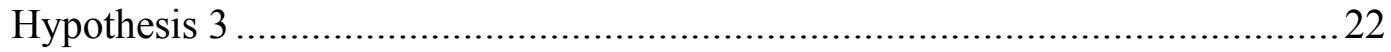

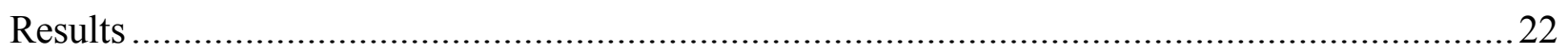

Preliminary Analyses: Overall Treatment Dropout and Demographics..........................22

Unconditional Random Intercept Only Model …………........................................26

Hypothesis 1: Early Therapeutic Alliance Predicting Treatment Dropout.......................26

Hypothesis 2: Client Age as a Moderator of Early Therapeutic Alliance Predicting

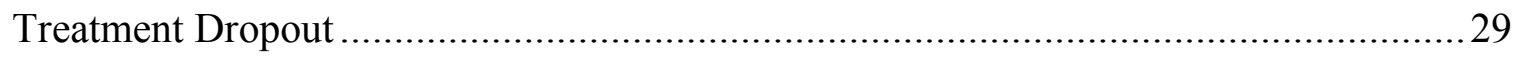

Hypothesis 3: Pretreatment Client PTSD Symptom Severity as a Moderator of Early

Therapeutic Alliance Predicting Treatment Dropout ....................................................... 31

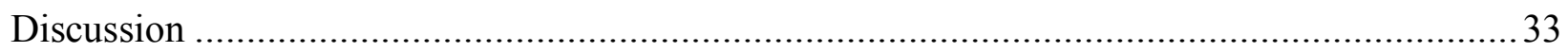

Early Therapeutic Alliance Predicting Treatment Dropout.............................................33

Moderators of the Early Therapeutic Alliance and Treatment Dropout Association ........36

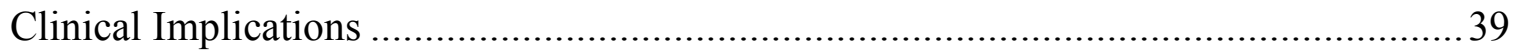

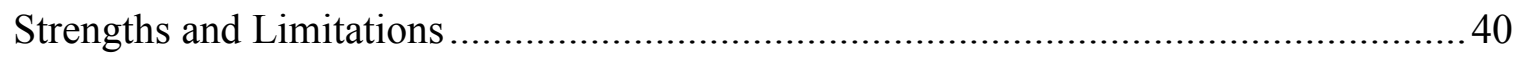

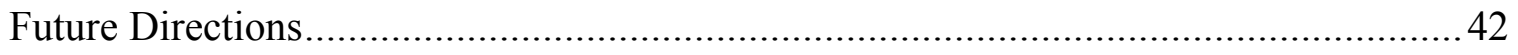

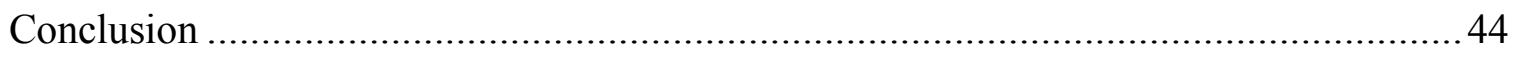

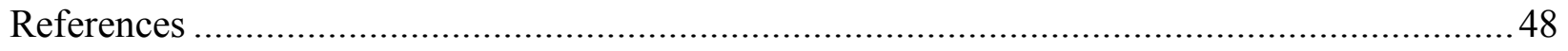




\section{List of Tables}

Table 1. Demographics of Therapist Sample........................................................... 23

Table 2. Demographics of Client Sample........................................................ 25

Table 3. Early Therapeutic Alliance Predicting Treatment Dropout from CPT in Multilevel

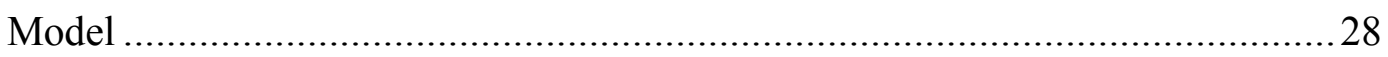

Table 4. Client Age as Moderator of Early Therapeutic Alliance and Dropout in Multilevel Model ........................................................................................... 30

Table 5. PTSD Severity as Moderator of Early Therapeutic Alliance and Dropout in

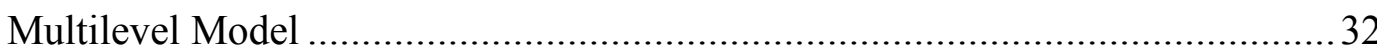




\section{List of Figures}

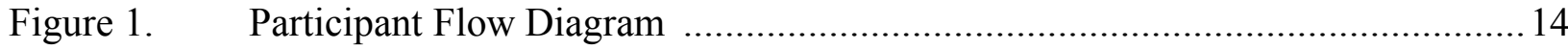




\section{List of Appendices}

Appendix A. Working Alliance Inventory-Observer Version-Short Form............................46 


\section{The Effect of Early Therapeutic Alliance on Treatment Dropout in Cognitive Processing Therapy and Client Factors as Moderators of This Relationship}

Approximately $76 \%$ of Canadians are exposed to a traumatic event and $10 \%$ of individuals are diagnosed with Posttraumatic Stress Disorder (PTSD) in their lifetime (Van Ameringen, Mancini, Patterson, \& Boyle, 2008). Left untreated, PTSD is a pernicious and debilitating condition that is associated with multiple personal and societal costs (Kessler, 2000; Van Ameringen et al., 2008). Fortunately, efficacious treatments have been developed for treating PTSD, including Cognitive Processing Therapy (CPT; Resick, Monson, \& Chard, 2017). CPT, along with Prolonged Exposure Therapy (PE; Foa, Hembree, \& Rothbaum, 2007), are Cognitive-Behavioural Therapies that are recommended as first-line evidence-based treatment approaches (American Psychological Association, 2017; Veterans Health Administration \& Department of Defense, 2017). Although these psychotherapies have been found to produce clinically significant reductions in PTSD symptoms (e.g., Watts et al., 2013), a substantial number of clients do not receive a full course of treatment due to therapy being terminated prematurely when clients drop out from treatment. Examining factors associated with treatment dropout may contribute to increasing our knowledge on how to tailor interventions in order to prevent treatment dropout before it occurs. Therefore, the purpose of this thesis is to examine the relationship between therapeutic alliance and treatment dropout, and potential moderators of this association.

\section{PTSD Treatment Dropout}

Various terms have been used to describe the occurrence of clients discontinuing psychotherapy without receiving a full course of treatment, including treatment dropout, premature termination, discontinuation, attrition, early withdrawal, and unilateral termination 
(Arnow et al., 2007; Eftekhari et al., 2014; Garfield, 1994; Tyron \& Kane, 1993). Within the PTSD literature, there have also been discrepancies in the ways in which treatment dropout is operationally defined. In randomized controlled trials (RCTs), treatment dropout is defined as when clients discontinue therapy after randomization to a treatment condition has occurred (Schnurr, 2007). Using this definition, clients may drop out before they even start treatment. Individuals who drop out are included in intention-to-treat analyses to provide the most unbiased treatment effect (Schnurr, 2007). However, in studies examining PTSD treatment dropout in clinical practice settings, dropout has been variably defined. For instance, in a study investigating predictors of treatment dropout from CPT and PE in a US Veterans Affairs outpatient clinic, Kehle-Forbes, Meis, Spoont, and Polusny (2016) characterized treatment dropout as individuals who did not have a final session clinical note indicating the protocol was completed and there were no other notes from the therapist indicating the reason for ending treatment. In this study, clients did not need to attend a certain number of sessions to be classified as completers, but they were required to have a final session note. In two other studies that examined PTSD treatment dropout in real-world clinical practice settings, the authors defined dropout as leaving treatment prior to reaching predetermined treatment goals that were made by both the client and therapist (Garcia, Kelley, Rentz, \& Lee, 2011; Zayfert et al., 2005). Treatment goals consisted of clients no longer meeting diagnostic criteria for PTSD and the client and therapist being satisfied with the outcome of treatment. In both of these studies, there was not a specific dosage of treatment, and thus the number of sessions at times exceeded those of standardized protocols. Mott and colleagues (2014) defined treatment dropout as clients who did not complete at least 7 sessions of the CPT or PE protocol. This definition of treatment dropout was based on research suggesting an average of 7.5 sessions are needed for positive treatment outcome in CPT 
(Galovski, Blain, Mott, Elwood, \& Houle, 2012) and a 7-session cutoff has been previously used to define PE completion (Yoder et al., 2012). The definitional variations of treatment dropout are important, because this influences the way in which researchers report treatment dropout rates (Wierzbicki \& Pekarik, 1993).

Regardless of operational definition, treatment dropout is a significant problem in evidence-based treatments for PTSD. It has been estimated that, on average, $28 \%$ of individuals in RCTs drop out of CPT or PE (Hembree et al., 2003; Watts et al., 2014) and an even greater percentage of clients drop out of treatment in real-world settings (Schottenbauer, Glass, Arnkoff, Tendick, \& Gray, 2008; Zayfert et al., 2005). For example, a study by Garcia and colleagues (2011) revealed that $68 \%$ of US veterans who served in Iraq/Afghanistan who were receiving PE or cognitive therapy through a Veterans Affairs clinic dropped out. In a smaller study of 33 clients who received either CPT or PE, only $21 \%$ completed treatment (DeViva, 2014). Gutner, Gallagher, Baker, Sloan, and Resick (2016) examined treatment dropout rates of civilian women with interpersonally violent traumas who received PE, CPT, CPT without written accounts, or CPT written accounts only. Across all treatment conditions, 39\% of clients dropped out. Based on these statistics, treatment dropout is a significant problem in both efficacy and effectiveness studies of PTSD treatment.

Clients who drop out of PTSD treatment prematurely are more likely to have poorer treatment outcomes (e.g., Zayfert et al., 2005). Since clients who drop out tend to do so early on in CPT, these individuals often continue to experience high levels of PTSD symptoms after they discontinue treatment (Kehle-Forbes et al., 2016). This is supported by RCT findings that demonstrate that completer samples have superior outcomes compared with intent-to-treat samples (Hembree et al., 2003). In addition to the negative consequences of treatment dropout 
experienced by clients, treatment dropout poses a problem for researchers, administrators, and therapists (George, 2008). For instance, in a research study, greater treatment dropout means missing data that could potentially impact the interpretability of results (Beckham, 1992) or compromise the study design (Ogrodniczuk, Joyce, \& Piper, 2005). From an administrative standpoint, treatment dropout could lead to wasted resources, impact wait lists, and a loss of revenue (Garfield, 1994; Masi, Miller, \& Olson, 2003; Ogrodniczuk et al., 2005). Therapists may also experience a sense of demoralization or experience of failure as a result of having clients who drop out (Sledge, Moras, Hartley, \& Levine, 1990).

\section{Therapeutic Alliance}

Therapeutic alliance, also known as working alliance, is recognized as an important variable in psychotherapy outcome. The concept of therapeutic alliance dates back to early psychoanalytic theory (e.g., Freud, 1958; Greenson, 1967; Zetzel, 1956) and has been studied for several decades. Although various definitions of therapeutic alliance exist, most researchers agree the alliance consists of three components: 1) an affective bond between the client and therapist; 2) mutually agreed upon goals between the client and therapist; and 3) the client and therapist's collaboration on assigned tasks (Bordin, 1979; Gaston, 1990; Horvath \& Symonds, 1991; Saunders, Howard, \& Orlinsky, 1989). Research on therapeutic alliance grew in an attempt to discover common elements across psychotherapies that contribute to positive outcomes, given the lack of consistent findings demonstrating differences in effectiveness across treatment modality (Martin, Garske, \& Davis, 2000). Some researchers have argued that therapeutic alliance may be a more important factor than the type of treatment administered in producing positive outcome (e.g., Safran \& Muran, 1995). 
A number of studies have found therapeutic alliance to be associated with treatment outcome. Four meta-analyses have investigated the relationship between therapeutic alliance and outcome and all found moderate effect size associations, ranging from $r=.22$ to $r=.28$ (Horvath \& Bedi, 2002; Horvath, Del Re, Flückiger, \& Symonds, 2011; Horvath \& Symonds, 1991; Martin et al., 2000). Therapeutic alliance has also been found to be correlated with treatment dropout. In their meta-analysis, Sharf, Primavera, and Diener (2010) examined the association between therapeutic alliance and treatment dropout across various treatment populations. The authors found that therapeutic alliance was negatively correlated with treatment dropout, with a medium effect size of $d=.55$. This finding indicates that clients with weaker therapeutic alliances were more likely to drop out of treatment, whereas clients with stronger therapeutic alliances were less likely to drop out (Sharf et al., 2010). This literature suggests therapeutic alliance is a key contributing factor to treatment dropout.

Some research suggests therapeutic alliance reported from the client's perspective is the strongest and most reliable predictor of treatment dropout and outcome (Horvath \& Symonds, 1991; Martin et al., 2000). Horvath (1994) posited that therapist ratings may be poorer predictors of outcome because therapists must make inferences about the client's beliefs about the alliance. This in turn, may lead to discrepancies between client and therapist-rated therapeutic alliance (Horvath, 1994). However, alliance rated by independent raters and clients have a comparable association with outcome (Horvath, 2001). For instance, Horvath and Symonds (1991) found that both client-rated and observer-rated therapeutic alliance were stronger predictors of outcome than therapist-rated therapeutic alliance. Furthermore, Elvins and Green (2008) argue that correlating alliance measures with an outcome measure from the same source (e.g., therapist reported alliance and outcome, or client reported alliance and outcome) can increase Type I 
errors. Thus, using observer-rated alliance scores overcomes this issue. Independent raters also have a higher degree of objectivity, and inter-rater reliability can be assessed to ensure accuracy of alliance ratings (Horvath \& Greenberg, 1986).

Therapeutic alliance measured early in treatment may be a particularly robust predictor of treatment outcome (Constantino, Castonguay, \& Schut, 2002; Horvath \& Greenberg, 1986). Various studies have found early ratings of therapeutic alliance to be more strongly correlated with outcome in comparison to later alliance ratings (Barber et al., 1999; Castonguay, Goldfried, Wiser, Raue, \& Hayes, 1996; Gaston, Gallager, Cournoyer, \& Gagnon, 1998; Joyce \& Piper, 1998). There is evidence that alliance measured as early as the first session may predict treatment dropout in various psychotherapies (Barber et al., 1999; Kokotovic \& Tracey, 1990; Tryon \& Kane, 1993). Averaging therapeutic alliance across sessions has a weaker association with outcome than alliance measured during the first third of treatment (Horvath, 2001). Using early alliance ratings is advantageous to late alliance ratings, because later ratings may be confounded with treatment benefits (Horvath, 2001). Specific to the PTSD literature, one study found alliance measured before session five during the skills training phase of CBT predicted a reduction of PTSD symptoms in a later phase of treatment involving trauma-focused intervention (Cloitre, Koenen, Cohen, \& Han, 2002).

A limited number of studies have examined the association between treatment dropout and early therapeutic alliance in samples of patients with a PTSD diagnosis. In Keller, Zoellner, and Feeny (2010)'s study, individuals with chronic PTSD completed a measure of therapeutic alliance at the beginning of sessions two and four of either PE or sertraline treatment. Across both treatment conditions, therapeutic alliance was positively associated with the total number of sessions completed. This suggests that as alliance scores increased, the total number of sessions 
completed also increased, and vice versa. Ormhaug and Jensen (2016) recruited 156 adolescents from Norway with significant posttraumatic stress symptoms and their caregivers to participate in either trauma-focused CBT or treatment as usual. Therapeutic alliance, rated by therapists, adolescents, and caregivers, was measured at session one of treatment. Results indicated that therapist-rated alliance scores were significantly associated with risk of treatment dropout, whereas parent- and youth-rated alliance scores were unrelated to treatment dropout. Although these studies suggest early therapeutic alliance is an important factor in relation to treatment dropout for those diagnosed with PTSD, previous studies have not explored this association in CPT.

CPT is a time-limited, trauma-focused, and manualized intervention for PTSD (Resick et al., 2017). CPT is built on Information Processing Theory that focuses on how traumatic events are interpreted and the consequences of these appraisals on beliefs about the present and future. Traditional cognitive interventions are used to modify these appraisals and beliefs. The intervention consists of 12 sessions that build upon each other, with new skills being introduced throughout treatment. Thus, the expectation is that clients will complete all 12 sessions. CPT consists of three phases. The first phase entails exploring the impact and meaning of the traumatic event, differentiating between thoughts and feelings, and identifying "stuck points". Stuck points are beliefs about why the trauma happened (e.g., "it is my fault the trauma happened") or beliefs the client holds about themselves, others, or the world (e.g., "I must be on guard at all times") that prevent processing of the traumatic event(s). The second phase focuses on appraisals about the traumatic event. The client is asked to write a detailed account of the trauma and stuck points related to self-blame and guilt are targeted in particular. The last phase 
focuses on altering stuck points that may have developed as consequences to the traumatic event(s) related to areas of safety, trust, power and control, esteem, and intimacy.

Treatment dropout can occur during any point of treatment. However, several studies have found that clients who drop out of CPT generally do so before their fourth session (Davis, Walter, Chard, Parkinson, \& Houston, 2013; Kehle-Forbes et al., 2016; Mott et al., 2014), which occurs during the first phase. This is particularly problematic since individuals who drop out early do so before problematic trauma appraisals have been challenged. Given the evidence that early therapeutic alliance predicts treatment dropout in other PTSD treatments, it is important to examine this relationship in the context of CPT. There may be important implications that arise if the negative association between early therapeutic alliance and treatment dropout demonstrates the same pattern in CPT. For instance, it would be imperative to determine ways to foster a strong alliance early on with clients to prevent treatment dropout from occurring before the critical stages of therapy begin.

\section{Moderators of Therapeutic Alliance and Treatment Dropout}

Research efforts to examine the association between early therapeutic alliance and treatment dropout in trauma-focused treatments are needed. Interpersonal issues are often evident in individuals with PTSD (e.g., lack of trust, negative beliefs about others; Price, Hilsenroth, Petretic-Jackson, \& Bonge 2001) and this may potentially interfere with the client's ability to form an alliance with their therapist. Moreover, there may be pre-existing client characteristics that have been found to predict treatment dropout that moderate the relationship between early therapeutic alliance and treatment dropout. Identifying such factors that contribute to treatment dropout has important clinical implications, because it may help clinicians tailor CPT in ways that prevent treatment dropout from occurring. For instance, increasing therapist awareness of 
certain factors that contribute to treatment dropout may encourage therapists to pay extra attention to strengthening therapeutic alliance with these clients early on in treatment and may help to target and tailor CPT to prevent treatment dropout. In addition, these findings may also be generalizable to other trauma-focused treatments in considering alterations to treatment delivery to prevent treatment dropout.

\section{Client Age}

Several studies examining between-group differences among individuals who drop out and those who complete PTSD treatment have found that those who drop out are younger (Cloitre, Stovall-McClough, Miranda, \& Chemtob, 2004; Foa et al., 2005; Goodson, Helstrom, Marino, \& Smith, 2017; Gros, Yoder, Tuerk, Lozano, \& Acierno, 2011; Kehle-Forbes et al., 2016). KehleForbes and colleagues (2016) examined client predictors of early and late treatment dropout in CPT and PE in a sample of US veterans. Veterans were categorized into one of three age groups: under 35 years old, 35 to 54 years old, or 55 years old or over. The authors found that veterans under 35 years of age were significantly more likely to dropout both early (before session 3) and late (after session 3 but before completion) than veterans over 55 years old. Veterans who were between 35 and 54 years old were more likely than older veterans to drop out of treatment early, but not late. Furthermore, Garcia and colleagues (2011) investigated pretreatment predictors of treatment dropout from both individual Cognitive Therapy (CT), individual PE, group CT, or individual or group CT combined with PE. Those who dropped out were significantly younger than those who completed treatment and younger age predicted treatment dropout. Rizvi, Vogt, and Resick (2009) examined predictors of treatment dropout in CPT and PE for women with PTSD related to sexual assault. Results indicated that age was negatively associated with treatment dropout and effects did not vary by treatment condition. Jeffreys and colleagues (2014) 
hypothesized that treatment dropout rates in CPT and PE would be higher for US Operation Enduring Freedom/Operation Iraqi Freedom/Operation New Dawn veterans than veterans from other eras. This was hypothesized based on prior literature that has found dropout rates to differ based on service era. However, they found that treatment dropout was accounted for by age, rather than by service era. Veterans who were older than 50 years old had a lower likelihood of dropping out.

Although there is a large body of literature that suggests age is negatively associated with treatment dropout, the reasons for this association are unclear. A potential reason proposed by Garcia and colleagues (2011) for their finding in a veteran sample is that younger males may hold more negative attitudes toward seeking help for psychological issues (Berger, Levant, McMillan, Kelleher, \& Sellers, 2005) and employ greater emotional restriction, consistent with traditional male norms (Levant \& Richmond, 2007). An alternative explanation is that younger individuals have more competing life responsibilities that may interfere with their commitment to treatment (Jeffreys et al., 2014). It may also be possible that younger clients have greater treatment ambivalence that leads to treatment dropout (Rizvi et al., 2009).

\section{Client Pretreatment PTSD Symptom Severity}

Another client factor that has been associated with treatment dropout is pretreatment PTSD symptom severity. Marks, Lovell, Noshivrani, Livanou, and Thrasher (1998) examined individuals who dropped out or completed various treatments (PE, cognitive restructuring, combined PE and cognitive restructuring, and relaxation). Clients who completed fewer than 11 weeks of treatment had more severe PTSD symptoms measured at pre-treatment. In a study investigating treatment dropout rates of imaginal exposure in clinical practice, treatment dropout rate was positively associated with overall pretreatment PTSD severity (Zayfert et al., 2005). In 
addition, treatment dropout was positively associated with avoidance and hyperarousal PTSD symptom clusters (Zayfert et al., 2005).

Garcia and colleagues (2011) examined US veteran clients who had dropped out of CT, PE, or combined treatment for PTSD. The authors found that treatment dropout was positively associated with self-reported overall PTSD symptom severity, in addition to symptoms of reexperiencing, avoidance/numbing, and hyperarousal. Furthermore, Bryant, Moulds, Guthrie, Dang, and Nixon (2003) explored treatment dropout among individuals assigned to imaginal exposure, cognitive restructuring, imaginal exposure combined with cognitive restructuring, or supportive counselling. In this study, treatment dropout was positively associated with severe symptoms of avoidance, but dropouts did not differ on other PTSD symptom clusters or overall PTSD symptomatology.

It should be noted that several studies have not found overall pretreatment PTSD symptom severity to predict treatment dropout in treatments for PTSD (Kehle-Forbes et al., 2016; Taylor, 2003; van Minnen, Arntz, \& Keijsers 2002). Additionally, some research suggests that pretreatment PTSD symptom severity may also be associated with therapeutic alliance. The research in this area, however, has been mixed. For instance, Ruglass (2005) found pretreatment PTSD hyperarousal symptoms to be significantly negatively correlated with therapeutic alliance. In another study, McLaughlin, Keller, Feeny, Youngstrom, and Zoellner (2014) did not find a significant relationship between early therapeutic alliance and pretreatment PTSD severity in PE. However, there is a dearth of literature examining whether initial PTSD symptom severity predicts treatment dropout in CPT. It may be possible that, even if pretreatment PTSD symptom severity does not have a direct influence on dropout, therapeutic alliance and PTSD symptom 
severity interact to produce an effect on dropout. Further research is needed to better understand this relationship in CPT.

\section{The Current Study}

To the author's knowledge, no prior studies have explored the relationship between therapeutic alliance and treatment dropout in CPT. Thus, the present study examined the relationship between observer-rated early therapeutic alliance and treatment dropout, as well as client age and pretreatment PTSD symptom severity, as potential predictors and moderators of this association.

\section{Hypotheses}

Based on the extant literature, the following hypotheses were offered:

1) It was hypothesized that early therapeutic alliance would be a significant predictor of treatment dropout. Specifically, there would be a negative association between therapeutic alliance and likelihood of treatment dropout.

2) It was hypothesized that client age would be significantly negatively associated with treatment dropout and would moderate the association between early therapeutic alliance and likelihood of treatment dropout. Specifically, decreasing age would strengthen the negative association between early therapeutic alliance and treatment dropout.

3) It was hypothesized that client PTSD symptom severity would be significantly positively associated with treatment dropout and would moderate the association between early therapeutic alliance and likelihood of treatment dropout. Specifically, increasing initial PTSD severity would strengthen the negative association between early therapeutic alliance and treatment dropout.

\section{Method}




\section{Participants}

All participants received CPT as part of a larger ongoing randomized implementation trial involving therapists and clients throughout Canada. The aim of the parent study was to examine two methods of post-training consultation to advance sustained and improved CPT delivery. Individuals who participated in a prior implementation trial as well as new clinicians who attended CPT workshops were recruited for the current study. Therapists recruited clients from their routine practice settings that included Operational Stress Injury Clinics, Canadian Forces Health Services clinics, hospitals, and private practices.

Therapists were recruited across Canada and were eligible to participate if they: 1) provided psychotherapy to individuals with PTSD; 2) agreed to provide CPT to 6 or more additional clients over the course of 2 years; 3 ) consented to be randomized to one of the two study conditions; 4) were willing to audio-record therapy sessions; and 5) had computer/internet access. The consultation conditions that therapists were randomized to included 1) Fidelityoriented Learning Community and 2) Continuous Quality Improvement Learning Community .

Participants in the present study were clients who either began CPT as part of this study and then dropped out, or clients who completed the CPT protocol. Figure 1 depicts the recruitment flow. Clients who completed 12 sessions of the CPT protocol were categorized as treatment completers. Completion was determined by noting the presence of a submitted session 12 PCL-5 measure or session 12 audio-recording. Clients who withdrew from treatment prior to session 12 due to early PTSD symptom remission $(n=4)$ were also considered to have completed treatment given prior studies that have characterized meeting treatment goals as evidence of completion (Garcia et al., 2011; Zayfert et al., 2005). Treatment dropout was defined as any client who did not complete the full treatment protocol of 12 CPT sessions. This was 


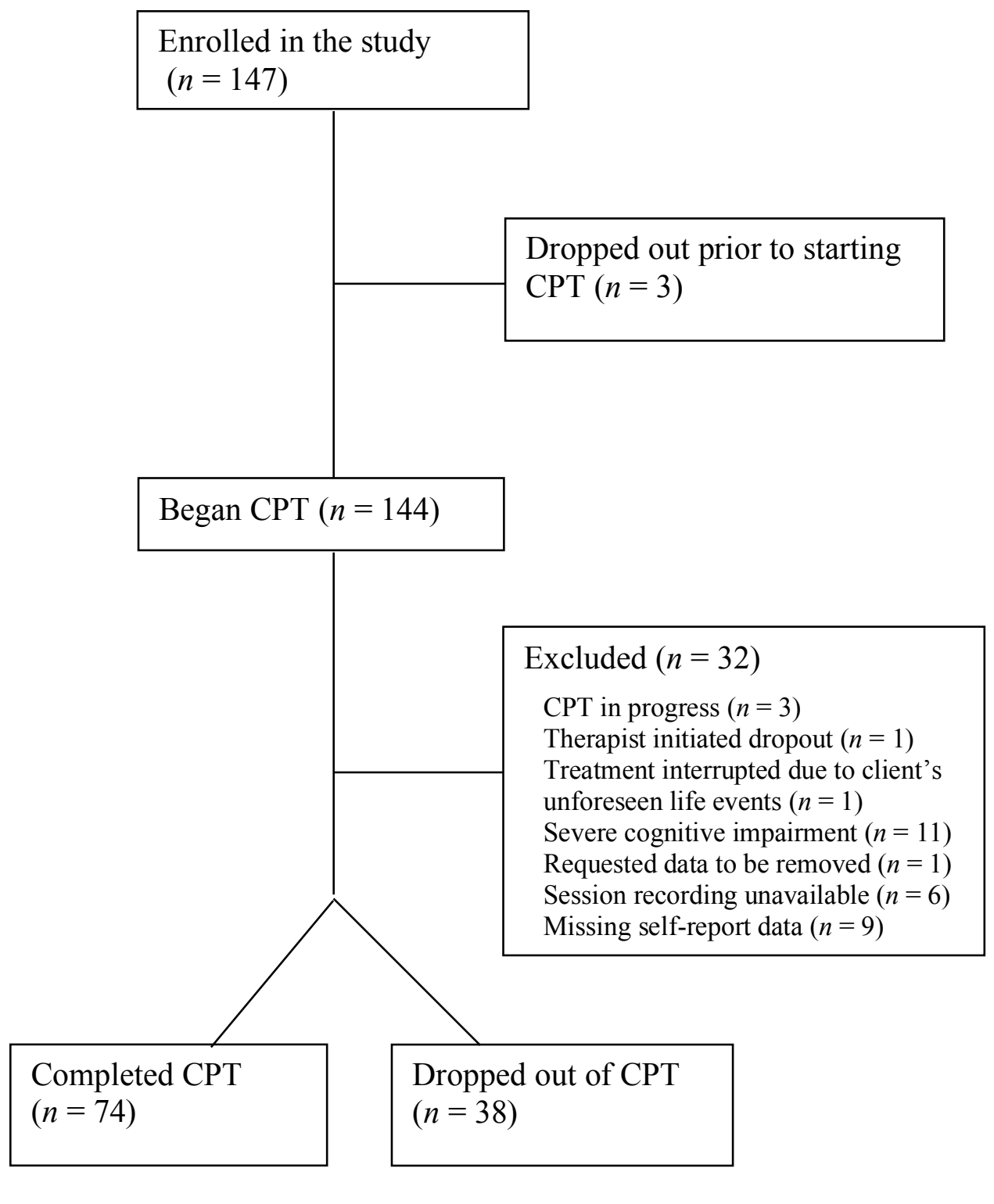

Figure 1. Flow diagram of participants in the study. 
determined by examining any missing weekly session measures that were submitted by therapists. To ensure that these measures were submitted due to treatment dropout rather than other reasons (e.g., technical issues, forgetting to send measures), therapists were contacted by study personnel to verify this. Therefore, dropouts were characterized as clients whose measures stopped prior to session 12 and had a therapist note confirming the client dropped out of the study. Several therapists did not respond back to emails inquiring if their clients dropped out. In these instances (for five clients who had less than 12 measures submitted) they were coded as dropouts.

Individuals who were enrolled in the study and dropped out prior to beginning therapy were excluded from analyses since prior research has suggested that clients who do not show up for therapy are different than those who begin treatment and then drop out (Baekeland \& Lundwall, 1975; Garfield, 1989). For instance, Garfield (1989) argues that clients should not be considered dropouts if they discontinued study participation after the assessment. Assessment and treatment are not synonymous; therefore, treatment dropouts should be defined as individuals who attended at least one treatment session. In addition, therapists who ended CPT with their clients due to location changes in their jobs were not included as treatment dropouts since dropout was not initiated by the client.

To be eligible to be enrolled in the study, clients had to: 1) have a current diagnosis of PTSD, with a minimum PTSD Checklist-5 (PCL-5; Weathers et al., 2013) score indicating a probable PTSD diagnosis; 2) have not previously received CPT; 3) be willing to complete symptom outcome measures and have their CPT sessions audio-recorded and reviewed by study personnel; and 4) be at least 18 years old. Clients were permitted to continue other psychotherapy if it did not specifically target PTSD symptoms. Exclusion criteria included: 1) 
current uncontrolled psychotic or bipolar disorder; 2) substance dependence requiring daily use or medical detoxification; 3) imminent suicide or homicide risk requiring immediate intervention; 4) and cognitive impairment that prevented engagement in therapy. Demographic characteristics including age, gender, education, and ethnicity are reported for both groups in the results section.

\section{Measures}

Therapeutic alliance was assessed by independent raters who listened to audio-recorded CPT sessions submitted by therapists. Clients completed self-report questionnaires prior to receiving CPT that included items related to demographic variables such as age. Prior to, as well as throughout treatment, clients completed measures that assessed their PTSD symptoms.

Working Alliance Inventory-Observer Version-Short Form (WAI-O-S). The WAI-

O-S (Tichenor \& Hill, 1989; Tracey \& Kokotovic, 1989) was used to measure therapeutic alliance and was completed by independent raters. This scale consists of 12 questions rated on 7point Likert scales, with two reverse scored items. A total therapeutic alliance score is calculated using the average across all items. Scores can range from 1 to 7 , with higher total scores indicate a stronger therapeutic alliance. The WAI-O-S was included as a part of the rating form used in the parent study. The raters were trained until there was $90 \%$ inter-rater reliability agreement within two points on the scale before independent study rating began. The intra-class correlation (ICC) between raters on early alliance ratings was good $(\mathrm{ICC}=.82)$.

The WAI-O-S is a widely used and accepted measure of therapeutic alliance (Martin et al., 2000). Although there has been more research conducted using the original WAI scale to demonstrate its reliability, the WAI-O-S has also been shown to have good reliability $(r=.81$; Gelfand \&DeRubeis, unpublished manuscript, cited in Andrusyna, Tang, DeRubeis \& Luborsky, 
2001). Cronbach's alpha was computed for the total score using the current sample of alliance ratings in the present study. A Cronbach's alpha of .95 was obtained, indicating a high level of internal consistency among items. Confirmatory factor analysis done with the original 36-item WAI supports the validity of a general alliance factor that was extracted to form the WAI-O-S (Tracey \& Kokotovic, 1989). Content, convergent, and discriminant validity have also been established for the 36-item WAI (Horvath, 1994).

PTSD Checklist-5 (PCL-5). The PCL-5 (Weathers et al., 2013) was used as a self-report measure of PTSD symptoms. The PCL-5 assesses the 20 DSM-5 symptoms of PTSD (American Psychiatric Association, 2013) and provides an overall PTSD severity score as well as scores for the four symptom clusters. This instrument consists of 20 items rated on a 5-point scale from 0 (not at all) to 4 (extremely), ranging from 0 to 80 , with higher total scores representing greater PTSD severity. The past week version, which assesses symptoms over the last week, was used in the current study. To determine pretreatment PTSD symptom severity, PCL-5 scores completed by clients immediately before session 1 were used. A score of 33 or higher can be used to make a probable PTSD diagnosis (Weathers et al., 2013).

The PCL-5 has been shown to be psychometrically sound. Several studies have found that this instrument has strong internal consistency, with Cronbach's alpha ranging from .91 - .96 (Armour et al., 2015; Blevins, Weathers, Davis, Witte, \& Domino, 2015; Bovin et al., 2015; Pietrzak et al., 2015; Wortmann et al., 2016). It also has high test-retest reliability ( $r=.82$ to $.84)$, as well as good convergent ( $r=.74$ to .87$)$ and discriminant validity $(r=.08$ to .60$)$ (Blevins et al., 2015; Bovin et al., 2015). The PCL-5 is sensitive to clinical change when comparing pre- to posttreatment scores (Wortmann et al., 2016).

\section{Treatment}


As described previously, CPT is a manualized intervention with a protocol that consists of 12 60-minute sessions. CPT has been found to be an effective treatment for PTSD in both military and civilian samples and for a range of traumatic experiences (Monson et al., 2006; Resick \& Schnike, 1992). In this treatment, PTSD is conceptualized as a disorder of nonrecovery in which the natural recovery process after a traumatic event has been stalled. The first session entails psychoeducation about what PTSD is, the rationale for the treatment, and provides clients an overview of the remainder of treatment. The next two sessions focus on making meaning of the traumatic event, using worksheets to differentiate thoughts from feelings, and finding stuck points that have interfered with the client's recovery process. Sessions four and five involve clients reading their written trauma accounts aloud and therapists using Socratic questioning to challenge stuck points, particularly those related to self-blame or guilt. Session six aims to teach clients to become their own therapists through the introduction of more worksheets. Sessions seven through 12 focus on areas that may have been impacted by the traumatic event including safety, trust, power and control, esteem, and intimacy.

\section{Procedure}

Clients were recruited through therapists in the study. Therapists obtained written informed consent from clients, which was forwarded to study personnel. Therapists were also responsible for administering the various measures pretreatment, during treatment, and after treatment. All audio-recorded sessions and measures were submitted by therapists to study personnel. Recordings of either sessions one, two, or three were utilized in the present study to obtain an alliance rating for each client and therapist dyad. Early session audio recordings were randomly selected to be rated by independent raters. Given that early sessions were randomly selected to be rated, 124 clients had one alliance rating, 30 had two alliance ratings, and three 
had three alliance ratings. This indicated that the majority of the clients (79\%) in the current sample only had one early session rating. Thus, if clients had more than one rating, the alliance rating to be used in the present study was randomly selected. The final sample of 112 alliance ratings consisted of 39 (34.8\%) session one ratings, 42 (37.5\%) session two ratings, and 31 (27.7\%) session three ratings. Raters were graduate level students in Clinical Psychology or postdoctoral fellows. Raters were kept blind to consultation condition, time spent in consultation, and clients' outcomes when rating sessions.

\section{Data Analytic Strategy}

No data were missing for the WAI-O-S although there was missing data for two clients who did not report their age as well as missing data on the PCL-5 measure. Missing data were handled using expectation maximization (EM), a form of maximum likelihood estimation that is known for providing unbiased parameter estimates while improving statistical power (Enders, 2001; Scheffer, 2002). Prior to utilizing the EM method, randomness of missing data was examined using Little's MCAR test (Little, 1988). Little's MCAR for the PCL-5 items and age revealed that the data were missing completely at random $\left(\chi^{2}(139)=152.63, p=.20\right)$. Thus, missing item-level data were imputed using EM. Nine clients had all 20 items of their session one PCL-5 incomplete and EM was not used as this method requires other observed values to impute estimates for the missing values. For these clients, an alternative missing data replacement method was evaluated by examining whether they had baseline PCL-5 scores (five of nine clients did). If so, these could be used in replacement of session one PCL-5 scores. To test if this would be an accurate imputation method, a difference score in the sample was calculated by subtracting PCL-5 session one scores from baseline scores to see how large the difference was in those who had both completed both measures. The range between scores was 
significantly large, varying from -19 to a 24-point difference and thus, it was deemed inappropriate to use baseline PCL-5 scores as a replacement score for these five clients. As a result, these nine clients were excluded from all analyses. The final sample used for analyses was 112 client-therapist dyads.

SPSS version 20.0 (IBM Corp, 2011) software was used to analyze data. The number of therapists in the final sample were 34 , and there were 112 clients in total, meaning that some clients were treated by the same therapist (i.e., nesting within therapist). Multilevel modelling (MLM) was used as this data analytic approach accounts for nesting of clients within therapists and is considered appropriate to use when assumptions of independence in linear regression models have been violated (Singer \& Willet, 2003). MLM was conducted through the generalized linear mixed models, logistic regression procedure. The current data contained two levels: clients (level 1), nested within therapists (level 2).

Prior to running models with the predictor variables, an unconditional (random intercept only) model was used to provide an estimate of the within and between variance in the outcome variable, treatment dropout. In this model, treatment dropout was predicted by the intercept that varied across therapists. The unconditional model describes the amount of heterogeneity between clusters through the intraclass correlation coefficient (ICC) and thus, provides a basis for analyzing the data in a multilevel approach (Glaser \& Hastings, 2011). The ICC for a binary logistic multilevel model is calculated by the random intercept variance (representing the between cluster variation) divided by $\pi^{2} / 3$ (representing the within cluster variation) plus the between cluster variation. Subsequent models were compared to this model to better understand how much variance was accounted for by adding predictors. Cohen's $d$ was calculated using the 
equation $d=\mathrm{t}(2 / \mathrm{n})^{1 / 2}$ (Dunlap, Cortina, Vaslow, \& Burke, 1996). Specific analyses conducted for each hypothesis are detailed below.

Hypothesis 1. It was hypothesized that early therapeutic alliance would be a significant predictor negatively associated with treatment dropout. This hypothesis was tested using MLM. The dependent variable, treatment dropout, was coded as a binary variable, with 0 representing treatment completion and 1 representing treatment dropout. This coding makes treatment completion status the reference category and treatment dropout status the target category. WAI$\mathrm{O}-\mathrm{S}$ was computed as a mean alliance score. For continuous predictors, centering variables to increase interpretability of results can be done in two ways in MLM: 1) group mean centering and 2) grand mean centering. When scores on a variable are deviated around the entire sample mean, it is grand mean centering. When scores on a variable are deviated around the means of a cluster variable, it is group mean centering. As scores on the WAI-O-S may be dependent on therapist effects, alliance was group mean centered. This was done through computing the average score across each cluster and then subtracting these scores from each individual WAI-O$\mathrm{S}$ score, providing an estimate of the deviation each individual has from their cluster.

Hypothesis 2. It was hypothesized that client age would be significantly negatively associated with treatment dropout and would moderate the association between early therapeutic alliance and likelihood of treatment dropout. As above, treatment dropout was the dichotomous outcome. Client age was grand mean centered. Grand mean centering was chosen because age is a variable that should not depend on the level 2 variable (therapist). Consistent with methods to test moderation (Cohen, Cohen, West, \& Aiken, 2003), the main effect of age and the moderator variable, computed by multiplying the centered alliance score by the centered age variable, was entered into the model to predict treatment dropout. 
Hypothesis 3. It was hypothesized that client PTSD symptom severity would be significantly positively associated with treatment dropout and would moderate the association between early therapeutic alliance and likelihood of treatment dropout. Similar to prior analyses, treatment dropout was coded as a dichotomous outcome and PTSD symptom severity was grand mean centered. The main effect of PCL-5 score and the moderator variable, computed by multiplying the centered alliance score by the centered PCL-5 variable, was entered into the model to predict treatment dropout.

\section{Results}

\section{Preliminary Analyses: Overall Treatment Dropout and Demographics}

Out of the 147 participants who enrolled into the study, 38 clients were categorized as having dropped out, resulting in an attrition rate of $25.9 \%$. Demographic characteristics of therapists in the study are presented in Table 1. Means of therapeutic alliance among those who dropped out and those who completed CPT were also examined. The clients who dropped out had an average therapeutic alliance score of $4.89(S D=.74)$ and those who completed CPT had a score of $4.89(S D=.77)$. The mean session one PCL-5 score was $53.18(S D=14.51)$ for those who dropped out, and $49.86(S D=14.54)$ for those who completed CPT. Correlations among all independent variables were computed. Correlations were computed using centered variables. Treatment dropout was not significantly associated with therapeutic alliance $(r=.03, p=.79)$, age $(r=-.08, p=.41)$, or PCL-5 scores $(r=.11, p=.23)$. Age was not correlated with PCL-5 scores $(r=.11, p=.27)$, and therapeutic alliance was not correlated with age $(r=-.004, p=.97)$ or PCL-5 scores $(r=-.03, p=.76)$. Demographic characteristics for clients who dropped out and those who completed CPT are included in Table 2. Independent samples $t$-tests were conducted to compare groups on age and level of education. Those who dropped out and those who 
Table 1

Demographics of Therapist Sample $(N=34)$

\begin{tabular}{|c|c|}
\hline Characteristic & $n(\%)^{\mathrm{a}}$ \\
\hline Age (M [SD]) & $39.88(8.61)$ \\
\hline \multicolumn{2}{|l|}{ Gender } \\
\hline Male & $8(23.5)$ \\
\hline Female & $26(76.5)$ \\
\hline \multicolumn{2}{|l|}{ Race/Ethnicity } \\
\hline White & $30(88.2)$ \\
\hline Black & $2(5.9)$ \\
\hline Latino & $1(2.9)$ \\
\hline Indigenous & $1(2.9)$ \\
\hline Years of Clinical Experience (M [SD]) & $10.44(6.28)$ \\
\hline \multicolumn{2}{|l|}{ Practice Setting } \\
\hline OSI Clinic or OTSSC & $11(32.3)$ \\
\hline Other Federal Health Service & $3(8.8)$ \\
\hline Provincial Health Agency & $6(17.6)$ \\
\hline Private Practice & $6(17.6)$ \\
\hline Community-Based Clinic or VA Hospital & $7(20.5)$ \\
\hline Other & $1(2.9)$ \\
\hline
\end{tabular}

Highest Educational Degree

$\mathrm{BA}, \mathrm{BS}$, or equivalent $\quad 6(17.6)$

MA, MSc, MSW, LCSW 14 (41.2) 
$\mathrm{PhD}$, PsyD, MD

$14(41.2)$

Note. ${ }^{\mathrm{a}}$ Data are presented as $n$ s with percentages (\%) unless otherwise indicated. BA $=$ Bachelor of Arts; BS = Bachelor of Science; LCSW = Licensed Clinical Social Worker MA = Master of Arts; $\mathrm{MD}=$ Medical Doctor; MSc $=$ Master of Science; MSW = Master of Social Work; OSI = Operational Stress Injury; OTSSC $=$ Operational and Trauma Stress Support Centres; $\mathrm{PhD}=$ Doctor of Philosophy; PsyD = Doctor of Psychology; VA = Veterans Affairs 
Table 2

Demographics of Client Sample $(N=112)$

\begin{tabular}{|c|c|c|c|}
\hline Characteristic & $\begin{array}{l}\text { Dropped out of } \\
\text { CPT }(n=38) \\
n(\%)^{\mathrm{a}}\end{array}$ & $\begin{array}{l}\text { Completed CPT } \\
\qquad \begin{array}{c}(n=74) \\
n(\%)^{\mathrm{a}}\end{array}\end{array}$ & Statistic \\
\hline Age (M [SD]) & $39.83(12.88)$ & $41.89(12.43)$ & $t(110)=.82 p=.41$ \\
\hline Gender & & & $p=.33$ \\
\hline Male & $18(47.4)$ & $41(55.4)$ & \\
\hline Female & $18(47.4)$ & $33(44.6)$ & \\
\hline Transgender & $1(2.6)$ & 0 & \\
\hline Years of Education (M [SD]) & $12.85(2.11)$ & $13.69(2.42)$ & $t(94)=1.59, p=.11$ \\
\hline Race/Ethnicity & & & $p=.64$ \\
\hline White & $32(84.2)$ & $59(79.7)$ & \\
\hline Black & $1(2.6)$ & $3(4.1)$ & \\
\hline Asian & $2(5.3)$ & $2(2.7)$ & \\
\hline Latino & $2(5.3)$ & $2(2.7)$ & \\
\hline Other & $2(5.3)$ & $8(10.8)$ & \\
\hline
\end{tabular}

Note. ${ }^{\mathrm{a}}$ Data are presented as $n$ s with percentages $(\%)$ unless otherwise indicated. 
completed CPT did not differ in age, $t(110)=.82 p=.41$, or years of education, $t(94)=1.59, p=$ .11. To examine differences between groups on gender and ethnicity, Fisher's Exact Tests were conducted as expected frequencies were too small for Chi-square tests. The two groups did not differ on gender, $p=.33$, two-tailed Fisher's exact test, or ethnicity, $p=.64$, two-tailed Fisher's exact test.

\section{Unconditional Random Intercept Only Model}

The ICC for the unconditional model was 0.081 , indicating that $8.1 \%$ of the variance in treatment dropout was due to therapist effects. Although there are no concrete rules for what number constitutes a high ICC, researchers across various disciplines suggest that an ICC of 5\% or greater is indicative of a clustering effect and thus clustering should be accounted for through the use of MLM (Glaser \& Hastings, 2011). Model fit may also be examined with indices such as the Akaike Information Criterion (AIC) or Bayesian Information Criterion (BIC). A decrease in the AIC or BIC across models suggests that the variables have predictive value and represent a better fitting model (Roberts, Monaco, Stovall, \& Foster, 2011). In the unconditional model, the AIC was 489.00 and the BIC was 491.68.

\section{Hypothesis 1: Early Therapeutic Alliance Predicting Treatment Dropout}

To test hypothesis 1, WAI-O-S, was added as a predictor of treatment dropout.

Originally, WAI-O-S was tested as a random effect to allow each client to have their own slope and intercept. However, the software produced an error message which suggested that the estimates of the model were unstable. The random effect covariance matrix indicated that the covariances across all predictors was zero. This suggests that there was not enough variation in the outcome to estimate an effect (Anderson \& Gerbing, 1984). Thus, the predictor in this model was entered as a fixed effect. The clustering variable, therapist, was entered as a random effect. 
Table 3 displays the results. The AIC was 489.48 and the BIC was 492.15, suggesting this model was slightly less favourable in predicting treatment dropout than the unconditional model in light of the increase in these values. 
Table 3

Early Therapeutic Alliance Predicting Treatment Dropout from CPT in Multilevel Model

\begin{tabular}{lccccc}
\hline Random Effect & $b$ & SE & $Z$ & $p$ & \\
\hline Intercept & 0.29 & 0.38 & 0.77 & .439 & $d$ \\
\hline Fixed Effect & $b$ & SE & $t$ & $p$ & -0.40 \\
\hline Intercept & -0.69 & 0.23 & -3.00 & .003 & .790 \\
WAI-O-S & 0.09 & 0.32 & 0.27 & & 0.04 \\
\hline
\end{tabular}

Note. WAI-O-S = Working Alliance Inventory-Observer Version-Short Form. 


\section{Hypothesis 2: Client Age as a Moderator of Early Therapeutic Alliance Predicting Treatment Dropout}

To test hypothesis 2, the main effect of age and the interaction term of WAI-O-S and age scores were added to the model. Once again, the therapist variable was entered as a random effect and the independent variables in the model (WAI-O-S, age, WAI-O-S*age) were entered as fixed effects. Table 4 displays the results. The AIC was 502.98 and the BIC was 505.62. The increase in these values from prior models suggests this model was less favourable than both the unconditional model and the model with WAI-O-S alone. 
Table 4

Client Age as Moderator of Early Therapeutic Alliance and Dropout in Multilevel Model

\begin{tabular}{lccccc}
\hline Random Effect & $b$ & SE & $Z$ & $p$ & \\
\hline Intercept & 0.37 & 0.42 & 0.89 & .374 & \\
\hline Fixed Effect & $b$ & SE & $t$ & $p$ & -0.39 \\
\hline Intercept & -0.70 & 0.23 & -2.95 & .004 & 0.03 \\
WAI-O-S & 0.08 & 0.33 & 0.23 & .816 & -0.12 \\
Age & -0.02 & 0.02 & -0.98 & .331 & -0.03 \\
WAI-O-S * Age & -0.00 & 0.03 & -0.25 & .804 & \\
\hline
\end{tabular}

Note. WAI-O-S = Working Alliance Inventory-Observer Version-Short Form. 


\section{Hypothesis 3: Pretreatment Client PTSD Symptom Severity as a Moderator of Early}

\section{Therapeutic Alliance Predicting Treatment Dropout}

To test hypothesis 3, the main effect of PCL-5 scores and the interaction term of WAI-O-

S and PCL-5 scores were added to the model. The therapist variable was entered as a random

effect and the independent variables in the model (WAI-O-S, PCL-5, WAI-O-S*PCL-5) were entered as fixed effects. Table 5 displays the results. The AIC was 503.47 and the BIC was

506.11. These values suggest this model was less favourable than both the unconditional model and the model with WAI-O-S alone. 
Table 5

PTSD Severity as Moderator of Early Therapeutic Alliance and Dropout in Multilevel Model

\begin{tabular}{lccccc}
\hline Random Effect & $b$ & SE & $Z$ & $p$ & \\
\hline Intercept & 0.33 & 0.40 & 0.81 & .415 & \\
\hline Fixed Effect & $b$ & SE & $t$ & $p$ & -0.40 \\
\hline Intercept & -0.70 & 0.24 & -2.97 & .004 & .910 \\
WAI-O-S & 0.04 & 0.33 & 0.11 & .219 & 0.17 \\
PCL-5 & 0.02 & 0.02 & 1.24 & .411 & 0.11 \\
WAI-O-S * PCL-5 & 0.02 & 0.02 & 0.83 & & \\
\hline
\end{tabular}

Note. PCL-5 = PTSD Checklist-5; WAI-O-S = Working Alliance Inventory-Observer VersionShort Form. 


\section{Discussion}

A significant number of clients do not receive a full course of CPT due to premature termination of therapy when clients drop out of treatment. In order to better tailor interventions to prevent treatment dropout, research examining factors associated with treatment dropout is needed. Thus, the current study investigated the role of early therapeutic alliance in predicting treatment dropout from CPT. Additionally, potential moderators of the alliance-dropout association (client age and pretreatment PTSD symptom severity) were examined. Based on extant literature, it was hypothesized that early therapeutic alliance would be a significant predictor negatively associated with likelihood of treatment dropout. The second hypothesis was that client age would be significantly negatively associated with treatment dropout and would moderate the association between early therapeutic alliance and likelihood of treatment dropout. Specifically, decreasing age would strengthen the negative association between early therapeutic alliance and treatment dropout. Lastly, it was hypothesized that pretreatment client PTSD symptom severity would be significantly positively associated with treatment dropout and would moderate the association between early therapeutic alliance and likelihood of treatment dropout. Specifically, increasing initial PTSD severity would strengthen the negative association between early therapeutic alliance and likelihood of treatment dropout. Contrary to expectation, these hypotheses were not supported. More specifically, therapeutic alliance did not significantly predict the likelihood of treatment dropout, and age and PTSD symptom severity were not significant predictors or moderators of the alliance-dropout association.

\section{Early Therapeutic Alliance Predicting Treatment Dropout}

The first aim of the study was to examine if early therapeutic alliance predicted treatment dropout. Given meta-analytic findings that therapeutic alliance is associated with outcome and 
dropout from treatment for a range of conditions (e.g., Horvath \& Bedi, 2002; Martin et al., 2000; Sharf et al., 2010), this was an important research question to explore specifically within CPT. It has been suggested that therapeutic alliance may be particularly important to form and maintain during treatment with individuals who have PTSD, because it may be difficult for those with PTSD to trust others or sustain interpersonal relationships (Dekel, Peleg, \& Solomon, 2013; Pedersen, 2017; Price et al., 2001). Cloitre and colleagues (2004) argue that the therapeutic alliance may reflect a repair in interpersonal disturbances and is a key ingredient in reducing PTSD symptoms. Although this association has been examined in other populations and in PTSD treatments such as PE, this was the first study to examine the relationship between early therapeutic alliance and treatment dropout in CPT.

Interestingly, in examining means of alliance scores in preliminary analyses, the means of early therapeutic alliance scores for those who dropped out and those who completed treatment were the same. The clients who dropped out had an average therapeutic alliance score of 4.89 $(S D=.74)$ and those who completed CPT had a score of $4.89(S D=.77)$. A similar mean of therapeutic alliance ratings between these groups was also reported in another study (Cloitre et al., 2004). The authors found that those who completed trauma-focused treatment and those who dropped out both had a mean rating of 6.3 on the client-reported WAI measure.

In this study, early therapeutic alliance did not predict likelihood of treatment dropout. In fact, the fit indices increased, suggesting poorer prediction of dropout with the inclusion of early therapeutic alliance as an independent variable. Three prior studies within the PTSD treatment literature found early therapeutic alliance to be associated with treatment dropout. However, differences in methodologies of the current study compared with prior studies may help explain this discrepancy. Keller and colleagues (2010) found that, in both sertraline and PE treatments 
for chronic PTSD, early therapeutic alliance was associated with the total number of sessions attended. Total number of sessions ranged from 0 to 10 and was not coded as a dichotomous dropout variable. In addition, therapeutic alliance was measured via client self-report. The relationship between therapeutic alliance and treatment dropout was analyzed using a bivariate correlation association and was not tested in a regression or multilevel framework. This makes it difficult to infer whether therapeutic alliance was a predictor of the number of sessions completed.

Investigating PTSD treatment in youth, Ormhaug and Jensen (2016) found variable associations between therapeutic alliance and dropout depending on the rater of therapeutic alliance. They found a significant association between therapist-rated therapeutic alliance and youth treatment dropout, but did not find associations between parent- or youth-rated therapeutic alliance and treatment dropout. Their methodology included defining treatment dropout by clinicians reporting whether treatment was completed or if the youth/parent chose to discontinue treatment. Moreover, the authors attempted to analyze their data using generalized estimating equations to account for nesting of data, but their models failed to converge. They consequently used binomial logistic regressions. Finally, Theodore (2015) found that client-rated therapeutic alliance measured at session three of PE predicted dropout in a one-tailed logistic regression analysis. The way in which treatment dropout was defined was not mentioned in this study. In sum, differences in methodology including definition of treatment dropout, timing of when therapeutic alliance was measured, by whom therapeutic alliance was rated, differences in treatments, and the type of statistical analyses used, may help explain differences in these findings and the current study's findings. 
The timing of alliance rating in the present study may have affected the findings of the current study as well. Therapeutic alliance measured at either session one, two, or three were examined in the present study, because early alliance has been shown to be a stronger predictor of outcomes across psychotherapies in comparison with later alliance ratings (Barber et al., 1999; Castonguay et al., 1996; Gaston et al., 1998; Joyce \& Piper, 1998). Using earlier ratings of therapeutic alliance is recommended, because later session ratings may be confounded with symptom improvement (Horvath, 2001). That said, Horvath and Luborsky (1993) posit that there are two critical therapeutic alliance phases. The first is in early sessions when the therapeutic alliance is being initially formed, which typically peaks during session three. The second phase is posited to be when the therapist begins to challenge the client through the use of more active interventions (Horavath \& Luborsky, 1993).

The first three sessions of CPT are predominately focused on psychoeducation and identifying connections between thoughts and feelings. It is possible that, if therapeutic alliance was measured during later sessions that involve challenging stuck points, there may have been differences in therapeutic alliance ratings among clients who dropped out compared with those who completed treatment. For instance, it is possible that individuals who had weaker alliances during this challenging phase, as Horvath and Luborsky (1993) posit, may have been more likely to drop out. However, it would be difficult to test this hypothesis as most individuals who drop out of CPT do so prior to the fourth session (Davis et al., 2013; Kehle-Forbes et al., 2016; Mott et al., 2014) and therefore alliance ratings for later sessions would not be available. This was the case in the present study as most individuals who dropped out, did so within the first three sessions.

Moderators of the Early Therapeutic Alliance and Treatment Dropout Association 
The second aim of this study was to examine potential moderators of the association between early therapeutic alliance and treatment dropout. Specific moderators that were investigated, based on prior studies, included client age and pretreatment PTSD symptom severity. Contrary to hypotheses, results indicated that neither client age nor pretreatment PTSD symptom severity predicted treatment dropout or moderated the relationship between early therapeutic alliance and treatment dropout. In fact, fit indices indicated poorer model fit with these variables included in the models.

Age was examined as a moderator of the alliance-dropout association based on several studies that have found age to be negatively associated with treatment dropout. However, age was not a significant predictor of treatment dropout or moderator of the association between alliance and treatment dropout in the current study. Contrary to the current study, prior studies have not treated age as a continuous variable. For example, Kehle-Forbes and colleagues (2016) found that age was a predictor of treatment dropout in CPT and PE in a sample of US veterans. They dichotomized age into three groups: under 35 years old, 35 to 54 years old, or 55 years old or over. Veterans who were under 35 years old were more likely to drop out of therapy than veterans over 55 years old. They also found that veterans between the ages of 35 to 54 were more likely to drop out of treatment early. Jeffreys and colleagues (2014) also categorized age into three groups: less than 30 , between 30 to 50 and greater than 50 . They defined dropout as completing less than two-thirds of recommended appointments. They found veterans who were older than 50 were less likely to drop out. Treating age as a continuous variable, Garcia and colleagues (2011) found that there was a negative association between age and likelihood of treatment dropout. Treatment dropout within this study was defined as terminating treatment prior to reaching predetermined treatment goals that were agreed upon by the therapist and 
client. Rizvi and colleagues (2009) also found that age was a significant predictor of treatment dropout in a sample of women sexual assault-related PTSD.

All of the aforementioned studies differ from the present study with regard to methodology. More specifically, some studies used correlations to analyze data or logistic regression models, treated age as a categorical variable, varied in the way they defined dropout, or collapsed dropout findings across treatments in studies where more than one treatment was compared. Additionally, some studies were conducted within specialty clinics, whereas others were RCTs. These studies were also conducted with veterans with combat trauma or women with sexual assault traumas. There may be differences in these associations because the current study was a community sample of individuals with diverse traumas.

Pretreatment PTSD symptom severity was also not a significant predictor of treatment dropout or moderator of early therapeutic alliance predicting treatment dropout in this study. It has been suggested that symptom severity may moderate the relationship between therapeutic alliance and outcome, with alliance being more important for clients with greater symptom severity (Horvath, 2001). This variable was examined as a moderator because it is possible that clients who have more severe PTSD symptoms may find it difficult to trust their therapists and form a therapeutic alliance early on, which may in turn potentially lead to treatment dropout. In comparison to client age, prior research that has examined PTSD symptom severity in relation to treatment dropout has been more mixed. Several studies have not found PTSD severity to be a predictor of dropout (Kehle-Forbes et al., 2016; Rizvi et al., 2009; Taylor, 2003; van Minnen et al., 2002). In studies that have found a positive association between pretreatment PTSD symptom severity and treatment dropout (e.g. Bryant et al., 2003; Garcia et al., 2011; Zayfert et al., 2005), none of the treatments examined were CPT. Thus, it may be possible that for CPT, initial PTSD 
symptom severity does not predict treatment dropout or have a moderating effect on the therapeutic alliance-dropout association. Instead, pretreatment symptom severity may be of greater importance to other trauma-focused treatments. As this is the only study that has examined pretreatment PTSD severity as a predictor of treatment dropout and moderator of the alliance-dropout association in CPT, more research is needed before drawing definitive conclusions.

\section{Clinical Implications}

Since treatment dropout in CPT and other trauma-focused treatments continues to be a major problem, this study has a number of clinical implications. Few studies to date have examined the role of therapeutic alliance in CPT. Laska, Smith, Wislocki, Minami, and Wampold (2013) examined themes that emerged from an interview with a clinical supervisor of therapists who were delivering CPT. One of the characteristics of effective therapists that emerged as a theme was the ability to develop a strong therapeutic alliance. Given the literature on the importance of therapeutic alliance in relation to dropout in other interventions, it was expected that there would be a similar significant association in CPT. Although the finding that therapeutic alliance did not predict likelihood of treatment dropout in the current study was unexpected, it may be encouraging for clinicians to know that their therapeutic alliance with clients may not be what leads individuals to drop out of treatment but that instead, other factors may be at play.

Preliminary analyses indicated that the mean score of early therapeutic alliance among

those who dropped out and those who completed CPT were toward the higher end of the measure that was used in the present study. This could serve as valuable information for clinicians who are new to CPT and are reluctant to use a manualized treatment due to worries that it may 
threaten the development of good therapeutic alliance. Additionally, average early therapeutic alliance scores of those who dropped out and those who completed CPT were the same, suggesting that clients who dropped out had good relationships with their therapists. Thus, the reasons why they dropped out may have been due to other factors that were not explored in the

current study. Indeed, further research on reasons for drop out is needed to better understand why clients discontinue treatment.

The absence of a moderating effect of these client variables may be viewed in a positive light. This may suggest that treatment dropout is not determined by baseline "static" variables such as age and PTSD symptom severity, as they interact with early therapeutic alliance. Thus, based on the study's findings, it may be suggested that clients with more severe PTSD symptoms or those who are younger will not necessarily form weaker alliances that are predictive of treatment dropout. Further research is needed to investigate other factors that could serve as moderators of the alliance-dropout association. This research would have clinical implications of defining specific groups of clients for whom CPT should be tailored to prevent dropout.

\section{Strengths and Limitations}

The present study has several strengths, including that therapeutic alliance was rated by expert independent raters. It has been argued that observer-rated measures of therapeutic alliance are preferable, because independent raters have a higher degree of objectivity and inter-rater reliability can be assessed (Horvath \& Greenberg, 1986). It also addresses concerns of shared method variance when patient-rated measures of alliance and outcomes are used. The inter-rater reliability for therapeutic alliance scores across raters was also measured and was good in the present study. Another strength of the present study was that it was based on a larger parent study, which was an implementation effectiveness trial. The clinicians were from a variety of 
diverse settings across Canada in this trial. Effectiveness trials have greater external validity, making them more generalizable to real-world clinical practice settings. Lastly, as there was nesting of clients within therapists, this study utilized MLM to account for clustering effects. Few prior studies in this area have used this analytic approach.

Although the present study had notable strengths, there were a number of limitations. First, PTSD was not established with the use of a clinician-administered diagnostic instrument. Rather, it was based on a cut-off score on the PCL-5 that indicated a probable PTSD diagnosis. Second, it was not always possible to confirm that the client had dropped out. Treatment dropout was determined by examining missing session measures and audio-recordings and then therapists were contacted to ensure that the client had indeed dropped out. However, for five clients, the therapists did not respond. Because these clients' outcome measures stopped prior to session 12 and there were no audio-recordings submitted for late sessions, they were categorized as having dropped out. Another limitation was that random effects of the predictors across models were not investigated. Although it would have been preferable to analyze the data using random effects models, it was not possible to test the models with this method due to non-convergence. This suggests that there was little variation in treatment dropout between the two groups. It is possible the individual slopes did not vastly differ across clients, and a random intercept was enough to capture the variation in the data (Anderson \& Gerbing, 1984). Furthermore, for complex models that include multiple predictors and random effects, larger sample sizes are recommended to better estimate effects (Schoeneberger, 2016). The sample size of clients and therapists in the current study may be considered small for MLM. Schoeneberger (2016) recommends that there be at least 50 level-1 units and 40 level-2 units for predicting fixed effects when intercept variances are small and slope variances are moderate. Lastly, a related limitation is that, in order 
to have enough statistical power, only a small number of variables could be examined in relation to treatment dropout.

The dropout rate of $25.9 \%$ in present study appeared to be slightly lower than rates reported in prior effectiveness trials of CPT (e.g., Schottenbauer et al., 2008; Zayfert et al., 2005). This treatment dropout rate may not be representative of other research trials. One possibility for the difference in this finding could be because the therapists in this sample chose to participate in this study after attending a CPT workshop and willingly agreed to provide CPT to at least six clients. It is possible that this gave rise to a self-selection bias, in which therapists in this trial were more interested in providing CPT and invested in their training than those in prior effectiveness trials that have examined treatment dropout. For example, the therapists in the current sample could have been more skilled at developing stronger therapeutic alliances with their clients. Therapist effects accounted for $8.1 \%$ of the variability in the outcome variable. This suggests that a proportion of treatment dropout can be explained simply by who the therapist was. Thus, differences in clinicians who took part in the present study in comparison with clinicians in other research trials should be taken into consideration.

\section{Future Directions}

As this was the first study examining the relationship between early therapeutic alliance and treatment dropout, as well as moderators of this relationship in CPT, further research is needed. Studies that examine therapeutic alliance in a different manner, such as specific dimensions of alliance (i.e., goal, task, bond) may be helpful to see if there are particular facets of therapeutic alliance that are more predictive of treatment dropout. Similarly, future studies should measure therapeutic alliance from more than one source. This includes therapist-, client-, and observer-perspectives to provide a richer understanding of therapeutic alliance and compare 
these in their ability to predict dropout. Research that investigates therapeutic alliance in later sessions of CPT, while controlling for symptom change, is also needed to understand if there are critical phases of alliance within this treatment and how this might influence treatment dropout. McLaughlin and colleagues (2014) found that unrepaired ruptures in therapeutic alliance were predictive of poorer treatment outcome in PE. Thus, it would be important for future studies to examine if ruptures in therapeutic alliance are predictive of treatment dropout in CPT.

Other client factors that were not investigated in the present study should be examined as potential predictors of treatment dropout and moderators of the alliance-dropout association in future research. For example, Brady, Warnock-Parkes, Barker, and Ehlers (2015) found that therapeutic alliance was significantly associated with in-session client expression of thoughts and feelings and preservative thinking (i.e., rumination related to the trauma). They also found that less expression of thoughts and feelings and greater preservative thinking were also associated with poorer outcomes in cognitive therapy for PTSD. Although these associations were examined using correlations, it is possible that these factors may interact with therapeutic alliance to predict treatment dropout. Moreover, Keller and colleagues (2010) found that early therapeutic alliance was significantly positively associated with homework adherence to PE and that positive trauma-related social support significantly predicted stronger early therapeutic alliance scores. Research on these factors has been limited. Thus, examining other pre-existing client characteristics and client process variables as predictors and moderators of the allianceoutcome association may be fruitful avenues for future research.

Examining therapist factors in relation to therapeutic alliance and treatment dropout is another important area of research. Therapist fidelity, the level of adherence and the competence in delivering a protocol, has been found to be positively associated with treatment outcome 
(McHugo, Drake, Teague, \& Xie, 1999). Furthermore, Brady and colleagues (2015) found that therapist competence was associated with therapeutic alliance. In another study, therapeutic alliance was found to influence adherence and competence in later sessions, suggesting that therapeutic alliance was a prerequisite for therapist fidelity (Weck, Grikscheit, Jakob, Höfling, \& Stangier, 2014). The relationship between therapist fidelity, therapeutic alliance, and treatment dropout is yet to be explored within CPT. Furthermore, the amount of therapist clinical experience that therapists have may be another variable to explore. Outside of the PTSD literature, some studies have found therapist clinical experience to be a predictor of treatment dropout (Swift \& Greenberg, 2012) and there is research that suggests clinical experience is related to therapeutic alliance (Bachelor \& Horvath, 1999; Hersoug, Hoglend, Monsen, \& Havik, 2001). However, the literature in this area has been mixed with other studies having not found therapist clinical experience to be a predictor of treatment dropout (e.g., George, 2008; Krauskopf, Baumgardner, \& Mandracchia 1981; Wierzbicki \& Pekarik, 1993). Investigating therapist variables in relation to therapeutic alliance and treatment dropout may be particularly useful in implementation trials similar to the present study in which therapists are learning a new treatment.

\section{Conclusion}

The current study adds to the body of literature that examines dropout behaviour in trauma-focused treatments. Given the various negative consequences that treatment dropout has on clients and therapists, this is an important empirical question to continue to explore. There is a dearth of research examining the role of therapeutic alliance in CPT. In the current study, early therapeutic alliance did not predict likelihood of treatment dropout and client age and pretreatment PTSD symptom severity did not moderate this association. Although the findings of 
the present study were contrary to expectation, this may suggest that individuals at risk of dropping out are still able to develop strong therapeutic alliances. In addition, specific subgroups (e.g., younger clients or those with more severe PTSD symptoms) may not be at a disadvantage in CPT based on these pre-existing baseline variables. Further research on therapeutic alliance and potential moderators of the alliance-dropout relationship that have yet to be explored, is needed to delineate the clinical implications for tailoring CPT in ways to prevent treatment dropout. 


\section{Appendix A}

\section{Working Alliance Inventory-Observer Version-Short Form}

Item 1: There is agreement about the steps taken to help improve the client's situation.

$\begin{array}{lrrrrrr}1 & 2 & 3 & 5 & 6 & 7 \\ \text { Never } & & & & \text { Always }\end{array}$

Item 2: There is agreement about the usefulness of the current activity in therapy (i.e., the client is seeing new ways to look at his/her problem).
1
2
3
4
5
6
7
Never
Always

Item 3: There is a mutual liking between the client and therapist.

$\begin{array}{lllllrr}1 & 2 & 3 & 4 & 5 & 6 & 7 \\ \text { Never } & & & & \text { Always }\end{array}$

Never

Item 4: There are doubts or a lack of understanding about what participants are trying to accomplish in therapy. *Item is a reverse scored item.
1
2
4
5
6
7
Never
Always

Item 5: The client feels confident in the therapist's ability to help the client.

$\begin{array}{lllllrr}1 & 2 & 3 & 4 & 5 & 6 & 7 \\ \text { Never } & & & & \text { Always }\end{array}$

Item 6: The client and therapist are working on mutually agreed upon goals.

$\begin{array}{llllrrr}1 & 2 & 3 & 5 & 5 & 6 & 7 \\ \text { Never } & & & & \text { Always }\end{array}$

Item 7: The client feels that the therapist appreciates him/her as a person.

$\begin{array}{lrrrrrr}1 & 2 & 3 & 4 & 5 & 6 & 7 \\ \text { Never } & & & & \text { Always }\end{array}$

Item 8: There is agreement on what is important for the client to work on.

$\begin{array}{lllllrr}1 & 2 & 3 & 5 & 5 & 6 & 7 \\ \text { Never } & & & & \text { Always }\end{array}$


Item 9: There is mutual trust between the client and therapist.

$\begin{array}{llllllr}1 & 2 & 3 & 4 & 5 & 6 & 7 \\ \text { Never } & & & & & & \text { Always }\end{array}$

Item 10: The client and therapist have different ideas about what the client's real problems are.

*Item is a reverse scored item.

$\begin{array}{lllllll}1 & 2 & 3 & 4 & 5 & 6\end{array}$

Never Always

Item 11: The client and therapist have established a good understanding of the changes that would be good for the client.

$\begin{array}{llllllr}1 & 2 & 3 & 4 & 5 & 6 & 7 \\ \text { Never } & & & & & \text { Always }\end{array}$

Never

Item 12: The client believes that the way they are working with his/her problem is correct.

$\begin{array}{llllllr}1 & 2 & 3 & 4 & 5 & 6 & 7 \\ \text { Never } & & & & & \text { Always }\end{array}$




\section{References}

American Psychiatric Association. (2013). Diagnostic and statistical manual of mental disorders ( $5^{\text {th }}$ ed.). Arlington VA: American Psychiatric Publishing.

American Psychological Association. (2017). Clinical practice guideline for the treatment of PTSD. Washington, DC. Retrieved from https://www.apa.org/ptsd-guideline/ptsd.pdf

Anderson, J. C., \& Gerbing, D. W. (1984). The effect of sampling error on convergence, improper solutions, and goodness-of-fit indices for maximum likelihood confirmatory factor analysis. Psychometrika, 49, 155-173. doi:10.1007/BF02294170

Andrusyna, T. P., Tang, T. Z., DeRubeis, R. J., \& Luborsky, L. (2001). The factor structure of The Working Alliance Inventory in cognitive-behavioral therapy. The Journal of Psychotherapy Practice and Research, 10, 173-178. Retrieved from https://www.ncbi.nlm.nih.gov/pmc/articles/PMC3330646/

Armour, C., Tsai, J., Durham, T. A., Charak, R., Biehn, T. L., Elhai, J. D., \& Pietrzak, R. H. (2015). Dimensional structure of $D S M-5$ posttraumatic stress symptoms: Support for a hybrid anhedonia and externalizing behaviors model. Journal of Psychiatric Research, 61, 106-113. doi:10.1016/j.jpsychires.2014.10.012

Arnow, B. A., Blasey, C., Manber, R., Constantino, M. J., Markowitz, J. C., Klein, D. N., .. . Rush, A. J. (2007). Dropouts versus completers among chronically depressed patients. Journal of Affective Disorders, 97, 197-202. doi:10.1016/j.jad.2006.06.017

Bachelor, A., \& Horvath, A. (1999). The therapeutic relationship. In M. A. Hubble, B. L. Duncan, \& S. D. Miller (Eds.), The heart and soul of change: What works in therapy (pp. 133-178). Washington, DC: APA Press. 
Baekeland, F., \& Lundwall, L. (1975). Dropping out of treatment: A critical review. Psychological Bulletin, 82, 738-783. doi:10.1037/ h0077132

Barber, J. P., Luborsky, L., Crtts-Christoph, P., Thase, M. E., Weiss, R., Frank, A., ... Gallop, R. (1999). Therapeutic alliance as predictor of outcome in treatment of cocaine dependence. Psychotherapy Research, 9, 54-73. doi:10.1093/ptr/9.1.54

Baruch, G., Vrouva, I., \& Fearon, P. (2009). A follow-up study of characteristics of young people that dropout and continue psychotherapy: Service implications for a clinic in the community. Child and Adolescent Mental Health, 14, 69-75. doi:10.1111/j.14753588.2008.00492.x

Beckham, E. E. (1992). Predicting patient dropout in psychotherapy. Psychotherapy: Theory, Research, Practice, Training, 29, 177-182. doi:10.1037/0033-3204.29.2.177

Berger, J. M., Levant, R. F., McMillan, K. K., Kelleher, W., \& Sellers, A. (2005). Impact of gender role conflict, traditional masculinity ideology, alexithymia, and age on men's attitudes toward psychological help seeking. Psychology of Men \& Masculinity, 6, 73-78. doi:10.1037/1524-9220.9.3.192

Blevins, C. A., Weathers, F. W., Davis, M. T., Witte, T. K., \& Domino, J. L. (2015). The Posttraumatic Stress Disorder Checklist for DSM-5 (PCL-5): Development and initial psychometric evaluation. Journal of Traumatic Stress, 28, 489-498. doi:10.1002/jts.22059

Bordin, E. S. (1979). The generalizability of the psychoanalytic concept of the working alliance. Psychotherapy: Theory, Research and Practice, 16, 252-260. doi:10.1037/h0085885 Bovin, M. J., Marx, B. P., Weathers, F. W., Gallagher, M. W., Rodriguez, P., Schnurr, P. P., \& Keane, T. M. (2015). Psychometric properties of the PTSD Checklist for Diagnostic and 
Statistical Manual of Mental Disorders-Fifth Edition (PCL-5) in Veterans. Psychological Assessment, 28, 1379-1391. doi:10.1037/pas0000254

Brady, F., Warnock-Parkes, E., Barker, C., \& Ehlers, A. (2015). Early in-session predictors of response to trauma-focused cognitive therapy for posttraumatic stress disorder. Behaviour Research and Therapy, 75, 40-47. doi:10.1016/j.brat.2015.10.001

Bryant, R. A., Moulds, M. L., Guthrie, R., Dang, S. T., \& Nixon, R. D. V. (2003). Imaginal exposure alone and imaginal exposure with cognitive restructuring in treatment of posttraumatic stress disorder. Journal of Consulting and Clinical Psychology, 71, 706-712. doi:10.1037/0022-006X.71.4.706

Castonguay, L. G., Constantino, M. J., \& Holtforth, M. G. (2006). The working alliance: Where are we and where should we go? Psychotherapy, 43, 271-279. doi:10.1037/00333204.43.3.271

Castonguay, L. G., Goldfried, M. R., Wiser, S., Raue, P. J., \& Hayes, A. M. (1996). Predicting the effect of cognitive therapy for depression: A study of unique and common factors. Journal of Clinical and Consulting psychology, 64, 497-504. doi:10.1037/0022006X.64.3.497

Charnas, J.W., Hilsenroth, M.J., Zodan, J., \& Blais, M.A. (2010). Should I stay or should I go? Personality Assessment Inventory and Rorschach indices of early withdrawal from psychotherapy. Psychotherapy: Theory, Research, Practice, Training, 47, 484-499. doi:10.1037/a0021180.

Cloitre, M., Koenen, K. C., Cohen, L. R., \& Han, H. (2002). Skills training in affective and interpersonal regulation followed by exposure: A phase-based treatment for PTSD related 
to childhood abuse. Journal of Consulting and Clinical Psychology, 70, 1067-1074. doi:10.1037/0022-006X.70.5.1067

Cloitre, M., Stovall-McClough, K. C., Miranda, R., \& Chemtob, C. M. (2004). Therapeutic alliance, negative mood regulation, and treatment outcome in child abuse-related posttraumatic stress disorder. Journal of Consulting and Clinical Psychology, 72, 411-416. doi:10.1037/0022-006X.72.3.411

Cohen, J., Cohen, P., West, S., \& Aiken, L. (2003). Applied multiple regression/correlation analysis for the behavioral sciences (3rd ed.). Mahwah, NJ: Lawrence Erlbaum.

Constantino, M. J., Castonguay, L. G., \& Schut, A. J. (2002). The working alliance: A flagship for the "scientist-practitioner" model in psychotherapy. In G. S. Tryon (Ed.), Counseling based on process research: Applying what we know (pp. 81-131). Boston: Allyn \& Bacon.

Davis, J. J., Walter, K. H., Chard, K. M., Parkinson, R. B., \& Houston, W. S. (2013). Treatment adherence in cognitive processing therapy for combat-related PTSD with history of mild TBI. Rehabilitation Psychology, 58, 36-42. doi:10.1037/a0031525

Dekel, S., Peleg, T., \& Solomon, Z. (2013). The relationship of PTSD to negative cognitions: A 17-year longitudinal study. Psychiatry, 76, 241-255. doi:10.1521/psyc.2013.76.3.241.

Defife, J.A., Conklin, C.Z., Smith, J.M., \& Poole, J. (2010). Psychotherapy appointment noshows: Rates and reasons. Psychotherapy: Theory, Research, Practice, Training, 47, 413417. doi: $10.1037 / \mathrm{a} 0021168$.

Derlega, V.J., McIntyre, R., Winstead, B.A., \& Morrow, G. (2001). A preliminary study of attraction-barrier model of patients' commitment and responses to dissatisfaction in psychotherapy. Psychotherapy: Theory, Research, Practice, Training, 38, 283-296. doi:10.1037/0033-3204.38.3.283 
DeViva, J. C. (2014). Treatment utilization among OEF/OIF veterans referred for psychotherapy for PTSD. Psychological Services, 11, 179-184. doi:10.1037/a0035077

Dunlap, W. P., Cortina, J. M., Vaslow, J. B., \& Burke, M. J. (1996). Meta-analysis of experiments with matched groups or repeated measures designs. Psychological Methods, 1 , 170-177. doi:10.1037/1082-989X.1.2.170

Eftekhari, A., Ruzek, J. I., Crowley, J. J., Rosen, C. S., Greenbaum, M. A., \& Karlin, B. E. (2013). Effectiveness of national implementation of prolonged exposure therapy in Veterans Affairs care. Journal of the American Medical Association Psychiatry, 70, 949955. doi:10.1001/jamapsychiatry.2013.36

Elvins, R., \& Green, J. (2008). The conceptualization and measurement of therapeutic alliance: An empirical review. Clinical Psychology Review, 28, 1167-1187. doi:10.1016/j.cpr.2008.04.002

Enders, C. K. (2001). A primer on maximum likelihood algorithms available for use with missing data. Structural Equation Modeling, 8, 128-141. doi:10.1207/S15328007SEM0801_7

Foa, E. B., Hembree, E. A., Cahill, S. P., Rauch, S. A. M., Riggs, D. S., Feeny, N. C., \& Yadin, E. (2005). Randomized trial of prolonged exposure for posttraumatic stress disorder with and without cognitive restructuring: Outcome at academic and community clinics. Journal of Consulting and Clinical Psychology, 73, 953- 964. doi:10.1037/0022-006x.73.5.953

Foa, E. B., Hembree, E. A., \& Rothbaum, B. O. (2007). Prolonged exposure therapy for PTSD: Emotional processing of traumatic experiences: Therapist guide. Oxford University Press, New York, NY. 
Freud, S. (1958). The dynamics of transference. In J. Starchey (Ed. \& Trans.), The standard edition of the complete psychological works of Sigmund Freud (Vol. 12, pp. 99-108). London: Hogarth Press.

Galovski, T. E., Blain, L. M., Mott, J. M., Elwood, L., \& Houle, T. (2012). Manualized therapy for PTSD: Flexing the structure of cognitive processing therapy. Journal of Consulting and Clinical Psychology, 80, 968-981. doi:10.1037/ a0030600

Garcia, H. A., Kelley, L. P., Rentz, T. O., \& Lee, S. (2011). Pretreatment predictors of dropout from cognitive behavioral therapy for PTSD in Iraq and Afghanistan war veterans. Psychological Services, 8, 1-11. doi:10.1037/a0022705

Garfield, S. L. (1989). Giving up on child psychotherapy: Who drops out? Comment on Weisz, Weiss, \& Langmeyer. Journal of Consulting and Clinical Psychology, 57, 168-169. doi:10.1037/0022-006X.57.1.168

Garfield, S. L. (1994). Research on client variables in psychotherapy? In A. E. Bergin \& S.L. Garfield (Eds.), Handbook of psychotherapy and behavior change (4th ed., pp. 190-228). New York: John Wiley \& Sons.

Gaston, L. (1990). The concept of the alliance and its role in psychotherapy: Theoretical and empirical considerations. Psychotherapy, 27, 143-153. doi:10.1037/0033-3204.27.2.143

Gaston, L., Gallaoer, D., Cournoyer, L., \& Gaonon, R. (1998). Alliance, technique, and their interactions in predicting outcome of behavioral, cognitive, and brief dynamic therapy. Psychotherapy Research, 8, 190-209. doi:10.1093/ptr/8.2.190

George, S. T. (2008). The effect of therapeutic alliance on client dropout: Hierarchical modeling of client feedback (Doctoral dissertation). Retrieved from ProQuest Dissertations \& Theses Database. (UMI No. AAI3303541). 
Glaser, D., \& Hastings, R. H. (2011). An introduction to multilevel modeling for anesthesiologists. Anesthesia and Analgesia, 113, 877-887. doi:10.1213/ANE.0b013e3182198a01

Goodson, J. T., Helstrom, A. W., Marino, E. J., \& Smith, R. V. (2017). The impact of serviceconnected disability and therapist experience on outcomes from prolonged exposure therapy with Veterans. Psychological Trauma: Theory, Research, Practice, and Policy. Advance online publication. doi:10.1037/tra0000260

Greenson, R. R. (1967). Technique and practice of psychoanalysis. New York: International Universities Press.

Gros, D. F., Yoder, M., Tuerk, P. W., Lozano, B. E., \& Acierno, R. (2011). Exposure therapy for PTSD delivered to veterans via telehealth: Predictors of treatment completion and outcome and comparison to treatment delivered in person. Behavior Therapy, 42, 276-283. doi:10.1016/j.beth.2010.07.005

Gutner, C. A., Gallagher, M. W., Baker, A. S., Sloan, D. M., \& Resick, P. A. (2016). Time course of treatment dropout in cognitive-behavioral therapies for posttraumatic stress disorder. Psychological Trauma: Theory, Research, Practice, and Policy, 8, 115-121. doi:10.1037/tra0000062

Hauck, S., Kruel, L., Sordi, A., Sbardelotto, G., Cervieri, A., Moschetti, L., . . F Freitas Caitlin, L.H. (2007). Factors related to early dropout in psychoanalytic psychotherapy. Revista de Psiquiatria do Rio Grande do Sul, 29, 265-267. doi:10.1590/ S0101-81082007000300005.

Hembree, E. A., Foa, E. B., Dorfan, N. M., Street, G. P., Kowalski, J., \& Tu, X. (2003). Do patients drop out prematurely from exposure therapy for PTSD? Journal of Traumatic Stress, 16, 555-562. doi:10.1023/B: JOTS.0000004078.93012.7d. 
Hersoug, A, G., Hoglend, P., Monsen, J. T., \& Havik, O. E. (2001). Quality of working alliance in psychotherapy: Therapist variables and patient/therapist similarities as predictors. Journal of Psychotherapy: Practice and Research, 10, 205-216. Retrieved from http://ezproxy.lib.ryerson.ca/login?url=https://search-proquestcom.ezproxy.lib.ryerson.ca/docview/619597829?accountid=13631

Horvath, A. O. (1994). Empirical validation of Bordin's pantheoretical model of the alliance: The working alliance inventory perspective. In A. O Horvath \& L. S. Greenberg (Eds.), The working alliance: Theory, research, and practice (pp. 109-128). New York: Wiley.

Horvath, A. O. (2001). The alliance. Psychotherapy: Theory, Research, Practice, Training, 38, 365-372. doi:10.1037/0033-3204.38.4.365

Horvath, A. O., \& Bedi, R. P. (2002). The alliance. In J. C. Norcross (Ed.), Psychotherapy relationships that work: Therapists contributions and responsiveness to patients (pp. 3769). New York: Oxford University Press.

Horvath, A. O., Del Re, A., Fluckiger, C., \& Symonds, D. B. (2011). Alliance in individual psychotherapy. Psychotherapy, 48, 9-16. doi:10.1037/a0022186

Horvath, A. O., \& Greenberg, L. S. (1986). Development of the Working Alliance Inventory. In L. S. Greenberg \& W. M. Pinsof (Eds.), The psychotherapeutic process: A research handbook (pp. 529-556). New York: Guilford.

Horvath, A. O., \& Luborsky, L. (1993). The role of the therapeutic alliance in psychotherapy. Journal of Consulting and Clinical Psychology, 61, 561-73. doi:10.1037//0022006X.61.4.561 
Horvath, A. O., \& Symonds, B. D. (1991). Relation between working alliance and outcome in psychotherapy: A meta-analysis. Journal of Counseling Psychology, 38, 139-149. doi:10.1037/0022-0167.38.2.139

IBM Corp. (2011). IBM SPSS Statistics for Windows, Version 20.0. Armonk, NY: IBM Corp.

Jeffreys, M. D., Reinfeld, C., Nair, P. V., Garcia, H. A., Mata-Galan, E., \& Rentz, T. O. (2014). Evaluating treatment of posttraumatic stress disorder with cognitive processing therapy and prolonged exposure therapy in a VHA specialty clinic. Journal of Anxiety Disorders, 28, 108-114. doi:10.1016/j.janxdis.2013.04.010

Joyce, A. S., \& Piper, W. E. (1998). Expectancy, the therapeutic alliance, and treatment outcome in short-term individual psychotherapy. Journal of Psychotherapy Practice and Research, 7, 236-248. Retrieved from https://www.ncbi.nlm.nih.gov/pmc/articles/PMC3330500/\#_ffn_sectitle

Kehle-Forbes, S., Meis, L. A., Spoont, M. R., \& Polusny, M. A. (2016). Treatment initiation and dropout from prolonged exposure and cognitive processing therapy in a VA outpatient clinic. Psychological Trauma: Theory, Research, Practice, and Policy, 8, 107-114. doi: $10.1037 / \operatorname{tra} 0000065$

Keller, S. M., Zoellner, L. A., \& Feeny, N. C. (2010). Understanding factors associated with early therapeutic alliance in PTSD treatment: adherence, childhood sexual abuse history, and social support. Journal of Consulting and Clinical Psychology, 78, 974-979. doi:10.1037/a0020758

Kessler, R. C. (2000). Post-traumatic stress disorder: The burden to the individual and to society. Journal of Clinical Psychiatry, 61, 171-181. Retrieved from http://onlinelibrary.wiley.com/journal/10.1002/(ISSN)1097-4679 
Kokotovic, A. M. \& Tracey, T. J. (1990). Working alliance in the early phase of counseling. Journal of Counseling Psychology, 37, 16-21. doi:10.1037/0022-0167.37.1.16.

Krauskopf, C. J., Baumgardner, A., \& Mandracchia, S. (1981). Return Rate Following Intake Revisited. Journal of Counseling Psychology, 28, 619-621. Retrieved from http://psycnet.apa.org/record/1982-04194-001

Laska, K. M., Smith, T. L., Wislocki, A. P., Minami, T., \& Wampold, B. E. (2013). Uniformity of evidence-based treatments in practice? Therapist effects in the delivery of cognitive processing therapy for PTSD. Journal of Counseling Psychology, 60, 31-41. doi:10.1037/a0031294

Levant, R. F., \& Richmond, K. (2007). A review of research on masculinity ideologies using the Male Role Norms Inventory. The Journal of Men's Studies, 15, 130-146. doi:10.3149/jms. 1502.130

Lingiardi, V., Filipucci, L., \& Baiocco, R. (2005). Therapeutic alliance evaluation in personality disorders psychotherapy. Psychotherapy Research, 15, 45-53. doi: $10.1080 / 10503300512331327047$

Little, R. J. A. (1988). A test of nissing completely at random for multivariate data with missing values. Journal of the American Statistical Association, 83, 11981202, doi:10.1080/01621459.1988.10478722

Marks, I. M., Lovell, K., Noshirvani, H., Livanou, M., \& Thrasher, S. (1998). Treatment of posttraumatic stress disorder by exposure and/or cognitive restructuring: A controlled study. Archives of General Psychiatry, 55, 317-325. doi:10.1080/10503300512331327047

Martin, D. J., Garske, J. P., \& Davis, M. K. (2000). Relation of therapeutic alliance with outcome and other variables: A meta-analytic review. Journal of Consulting and 
Clinical Psychology, 68, 438-450. doi:IO.I037//0022-006X.68.3.438

Masi, M. V., Miller, R. B., \& Olson, M. M. (2003). Differences in dropout rates among individual, couple, and family therapy clients. Contemporary Family Therapy: An International Journal, 25, 63-75. doi:10.1023/A:1022558021512

McHugo, G. J., Drake, R. E., Teague, G. B., \& Xie, H. (1999). Fidelity to assertive community treatment and client outcomes in the New Hampshire dual disorders study. Psychiatric Services, 50, 818-824. doi:10.1176/ps.50.6.818

McLaughlin, A. A., Keller, S. M., Feeny, N. C., Youngstrom, E. A., \& Zoellner, L. A. (2014). Patterns of therapeutic alliance: rupture-repair episodes in prolonged exposure for posttraumatic stress disorder. Journal of Consulting and Clinical Psychology, 82, 112-121. doi:10.1037/a0034696

Monson, C. M., Schnurr, P. P., Resick, P. A., Friedman, M. J., Young-Xu, Y., \& Stevens, S. P. (2006). Cognitive processing therapy for veterans with military-related posttraumatic stress disorder. Journal of Consulting and Clinical Psychology, 74, 898-907. doi:10.1037/0022006X.74.5.898

Morlino, M., Di Pietro, G., Tuccillo, R., Galietta, A., Bolzan, M., Senatore, I., . . Valoroso, L. (2007). Drop-out rate in eating disorders: Could it be a function of patient-therapist relationship? Eating and Weight Disorders, 12, 64-67. Retrieved from https://www.ncbi.nlm.nih.gov/pubmed/17984632

Mott, J. M., Mondragon, S., Hundt, N. E., Beason-Smith, M., Grady R. H., \& Teng E. J. (2014). Characteristics of U.S. veterans who begin and complete prolonged exposure and cognitive processing therapy for PTSD. Journal of Traumatic Stress, 27, 265-73. doi: $10.1002 /$ jts. 21927 
Ogrodniczuk, J. S., Joyce, A. S., \& Piper, W. E. (2005). Strategies for reducing patient-initiated premature termination of psychotherapy. Harvard Review of Psychiatry, 13, 57-70. doi:10.1080/10673220590956429

Ormhaug, S. M. \& Jensen, T. K. (2016). Investigating treatment characteristics and first-session relationship variables as predictors of dropout in the treatment of traumatized youth.

Psychotherapy Research. Advance online

publication. doi:10.1080/10503307.2016.1189617

Pedersen, A. H. (2017). An examination of therapeutic alliance during prolonged exposure in the treatment of a comorbid PTSD and SUD population (Doctoral dissertation). Retrieved from ProQuest Dissertations \& Theses Database. (UMI No. 10606211).

Perry, J. P., Bond, M., \& Roy, C. (2007). Predictors of treatment duration and retention in a study of long-term dynamic psychotherapy: Childhood adversity, adult personality, and diagnosis. Journal of Psychiatric Practice, 13, 221-232.

doi:10.1097/01.pra.0000281482.11946.fc

Pietrzak, R. H., Tsai, J., Armour, C., Mota, N., Harpaz-Rotem, I., \& Southwick, S. M. (2015). Functional significance of a novel 7-factor model of DSM-5 PTSD symptoms: Results from the National Health and Resilience in Veterans study. Journal of Affective Disorders, 174, 522-526. doi:10.1016/j.jad.2014.12.007

Price, J., Hilsenroth, M., Petretic-Jackson, P., \& Bonge, D. (2001). A review of individual psychotherapy outcomes for adult survivors of childhood sexual abuse. Clinical Psychology Review, 21, 1095-1121. doi:10.1016/S0272-7358(00)00086-6 
Reis, B. F., \& Brown, L. G. (1999). Reducing psychotherapy dropouts: Maximizing perspective convergence in the psychotherapy dyad. Psychotherapy, 36, 123-136. doi: $10.1037 / \mathrm{h} 0087822$

Resick, P. A., Monson, C. M., \& Chard, K. M. (2017). Cognitive processing therapy for PTSD: A comprehensive manual. New York: Guilford.

Resick, P. A., \& Schnicke, M. K. (1992). Cognitive processing therapy for sexual assault victims. Journal of Consulting and Clinical Psychology, 60, 748-756. doi:10.1037/0022006X.60.5.748

Rizvi, S. L., Vogt, D. S., \& Resick, P. A. (2009). Cognitive and affective predictors of treatment outcome in cognitive processing therapy and prolonged exposure for posttraumatic stress disorder. Behaviour Research and Therapy, 47, 737-743. doi:10.1016/j.brat.2009.06.003

Roberts, J. K., Monaco, J. P., Stovall, H., \& Foster, V. (2011). Explained variance in multilevel models. In J. J. Hox, \& J. K. Roberts (Eds.), Handbook for advanced multilevel analysis (pp. 219-230). New York, NY: Routledge/Taylor \& Francis Group.

Ruglass, L. M. (2005). Ethnocultural differences in therapeutic alliance and outcome for women with comorbid posttraumatic stress disorder and substance use disorder. (Doctoral dissertation). Retrieved from ProQuest Dissertations \& Theses Database. (UMI No. AAI3184390).

Safran, J. D., \& Muran, J. C. (Eds.). (1995). The therapeutic alliance [Special issue]. In Session: Psychotherapy in Practice, 1.

Samstag, L. W., Muran, J. C., Wachtel, P. L., Slade, A., Safran, J. D., \& Winston, A. (2008). Evaluating negative process: A comparison of working alliance, interpersonal behavior, and narrative coherency among three psychotherapy outcome conditions. American 
Journal of Psychotherapy, 62, 165-194. Retrieved from

http://ezproxy.lib.ryerson.ca/login?url=http://search.proquest.com/docview/622131036?acc ountid=13631

Saunders, S. M., Howard, K. I., \& Orlinsky, D. E. (1989). The therapeutic bond scales: Psychometric characteristics and relationship to treatment effectiveness. Psychological Assessment, 1, 323-330. doi:10.1037/1040-3590.1.4.323

Scheffer, J. (2002). Dealing with missing data. Research Letters in the Information and Mathematical Sciences, 3, 153-160. Retrieved from http://equinetrust.org.nz/massey/fms/Colleges/College\%20of\%20Sciences/IIMS/RLIMS/V olume03/Dealing_with_Missing_Data.pdf

Schnurr, P. P. (2007). The rocks and hard places in psychotherapy outcome research. Journal of Traumatic Stress, 20, 779-792. doi:10.1002/jts.20292

Schoeneberger, J. A. (2016). The impact of sample size and other factors when estimating multilevel logistic models. Journal of Experimental Education, 84, 373-397. Retrieved from http://dx.doi.org.ezproxy.lib.ryerson.ca/10.1080/00220973.2015.1027805

Schottenbauer, M. A., Glass, C. R., Arnkoff, D. B., Tendick, V., \& Gray, S. H. (2008). Nonresponse and dropout rates in outcome studies on PTSD: Review and methodological considerations. Psychiatry, 71, 134-168. doi:10.1521/psyc.2008.71.2.134

Sharf, J., Primavera, L. H., \& Diener, M. J. (2010). Dropout and therapeutic alliance: a metaanalysis of adult individual psychotherapy. Psychotherapy, 47, 637-645. doi:10.1037/a0021175

Singer, J. D., \& Willett, J. B. (2003). Applied longitudinal data analysis: Modeling change and event occurrenc. New York, NY: Oxford University Press. 
Sledge, W. H., Moras, K., Hartley, D., \& Levine, M. (1990). Effect of time-limited psychotherapy on patient dropout rates. American Journal of Psychiatry, 147, 1341-1347. doi:10.1176/ajp.147.10.1341

Swift, J. K., \& Greenberg, R. P. (2012). Premature discontinuation in adult psychotherapy: A meta-analysis. Journal of Consulting and Clinical Psychology, 80, 547-559. doi: $10.1037 / \mathrm{a} 0028226$

Taylor, S. (2003). Outcome predictors for three PTSD treatments: Exposure therapy, EMDR, and relaxation training. Journal of Cognitive Psychotherapy, 17, 149-161. doi:10.1891/jcop.17.2.149.57432

Theodore, Z. (2016). The relationship between the therapeutic alliance and treatment outcome in prolonged exposure therapy for PTSD (Doctoral dissertation). Retrieved from ProQuest Dissertations \& Theses Database. (UMI No. 10188170).

Tichenor, V., \& Hill, C. E. (1989). A comparison of six measures of the working alliance. Psychotherapy: Research and Practice, 26, 195-199. Retreived from http://psycnet.apa.org/index.cfm?fa=buy.optionToBuy\&id=1989-31681-001

Tracey, T. J., \& Kokotovic, A. M. (1989). Factor structure of the Working Alliance Inventory. Psychological Assessment: A Journal of Consulting and Clinical Psychology, 1, 207-210. doi:10.1037/1040-3590.1.3.207

Tryon, G. S., \& Kane, A. S. (1993). Relationship of working alliance to mutual and unilateral termination. Journal of Counseling Psychology, 40, 33-36. Retrieved from http://psycnet.apa.org/index.cfm?fa=buy.optionToBuy\&id=1993-14521-001

Van Ameringen, M., Mancini, C., Patterson, B., \& Boyle, M. H. (2008). Post-traumatic stress disorder in Canada. CNS Neuroscience \& Therapeutics, 14, 171-181. doi:10.1111/j.1755- 
5949.2008.00049.x

van Minnen, A., Arntz, A., \& Keijsers, G. (2002). Prolonged exposure in patients with chronic PTSD: Predictors of treatment outcome and dropout. Behaviour Research and Therapy, 40, 439-457. doi:10.1016/S0005-7967(01)00024-9

Veterans Health Administration \& Department of Defense. (2017). VA/ DoD clinical practice guideline for the management of post-traumatic stress. Washington, DC. Retrieved from https://www.healthquality.va.gov/guidelines/MH/ptsd/VADoDPTSDCPGFinal012418.pdf

Watts, B. V., Schnurr, P. P., Mayo, L., Young-Xu, Y., Weeks, W. B., \& Friedman, M. J. (2013). Meta-analysis of the efficacy of treatments for posttraumatic stress disorder. Journal of Clinical Psychiatry, 74, 541-550. doi:10.4088/JCP.12r08225

Watts, B. V., Shiner, B., Zubkoff, L., Carpenter-Song, E., Ronconi, J. M., \& Coldwell, C. M. (2014). Implementation of evidence-based psychotherapies for posttraumatic stress disorder in VA specialty clinics. Psychiatry Services, 65, 648-53. doi:10.1176/appi.ps.201300176.

Weathers, F. W., Litz, B. T., Keane, T. M., Palmieri, P. A., Marx, B. P., \& Schnurr, P. P. (2013). The PTSD Checklist for DSM-5 (PCL-5). Scale available from the National Center for PTSD at www.ptsd.va.gov.

Weck, F., Grikscheit, F., Jakob, M., Höfling, V., \& Stangier, U. (2014). Treatment failure in cognitive-behavioural therapy: Therapeutic alliance as a precondition for an adherent and competent implementation of techniques. British Journal of Clinical Psychology, 54, 91108. doi:10.1111/bjc.12063

Wierzbicki, M., \& Pekarik, G. (1993). A meta-analysis of psychotherapy dropout. Professional Psychology: Research and Practice, 24, 190-195. doi:10.1037/0735-7028.24.2.190 
Wortmann, J. H., Jordan, A. H., Weathers, F. W., Resick, P. A., Dondanville, K. A., Hall-Clark, ... Litz, B. T. (2016). Psychometric analysis of the PTSD Checklist-5 (PCL-5) among treatment-seeking military service members. Psychological Assessment. Advance online publication. doi: $10.1037 /$ pas0000260

Yoder, M., Tuerk, P. W., Price, M., Grubaugh, A. L., Strachan, M., Myrick, H., \& Acierno, R. (2012). Prolonged exposure therapy for combat-related posttraumatic stress disorder: Comparing outcomes for veterans of different wars. Psychological Services, 9, 16-25. doi:10.1037/a0026279

Zayfert, C., Deviva, J. C., Becker, C. B., Pike, J. L., Gillock, K. L., \& Hayes, S. A. (2005). Exposure utilization and completion of cognitive behavioral therapy for PTSD in a "real world" clinical practice. Journal of Traumatic Stress, 18, 637-645. doi:10.1002/jts.20072

Zetzel, E. R. (1956). Current concepts of transference. International Journal of Psychoanalysis, 37, 369-376. Retrieved from https://www.ncbi.nlm.nih.gov/pubmed/13366506 